\title{
Common and Contrasting Genomic Profiles among the Major Human Lung Cancer Subtypes
}

\author{
G. Tonon,${ }^{\S}$ C. Brennan, ${ }^{*}$ A. Protopopov, ${ }^{\S}$ G. Maulik, ${ }^{*}$ B. FenG,${ }^{\S}$ Y. Zhang, ${ }^{\S}$ \\ D.B. Khatry ${ }^{\S}$ M.J. You, ${ }^{\dagger}$ A.J. Aguirre, ${ }^{*}$ E.S. MARTin, ${ }^{*}$ Z. Yang, ${ }^{*}$ H. Ji, ${ }^{*}$ L. Chin, ${ }^{\S}$ \\ K.-K. Wong, ${ }^{*}$ AND R.A. DePINHO, $₫$ đI \\ *Departments of Medical Oncology and ${ }^{\S}$ Center for Applied Cancer Science, Dana-Farber Cancer Institute; \\ ${ }^{\dagger}$ Department of Pathology, Brigham and Women's Hospital; Department of Dermatology, and \\ ${ }^{\pi}$ Department of Genetics and Medicine, Harvard Medical School, Boston, Massachusetts 02115
}

\begin{abstract}
Lung cancer is the leading cause of cancer mortality worldwide. With the recent success of molecularly targeted therapies in this disease, a detailed knowledge of the spectrum of genetic lesions in lung cancer represents a critical step in the development of additional effective agents. An integrated high-resolution survey of regional amplifications and deletions and gene expression profiling of non-small-cell lung cancers (NSCLC) identified 93 focal high-confidence copy number alterations (CNAs), with 21 spanning less than $0.5 \mathrm{Mb}$ with a median of five genes. Most CNAs were novel and included high-amplitude amplification and homozygous deletion events. Pathogenic relevance of these genomic alterations was further reinforced by their recurrence and overlap with focal alterations of other tumor types. Additionally, the comparison of the genomic profiles of the two major subtypes of NSCLC, adenocarcinoma (AC) and squamous cell carcinoma (SCC), showed an almost complete overlap with the exception of one amplified region on chromosome 3, specific for SCC. Among the few genes overexpressed within this amplicon was p63, a known regulator of squamous cell differentiation. These findings suggest that the AC and SCC subtypes may arise from a common cell of origin and they are driven to their distinct phenotypic end points by altered expression of a limited number of key genes such as p63.
\end{abstract}

Lung cancer is the leading cause of cancer-related mortality in the United States, accounting for more than onefourth of all cancer fatalities in 2004. Distinctive clinical and pathobiological features serve to classify lung cancers into two major subtypes: small-cell lung cancer (SCLC) and non-small-cell lung cancer (NSCLC). NSCLC constitutes $75 \%$ of lung cancer cases and is subdivided further into three major histologically distinct subtypes, including adenocarcinoma (AC), squamous cell carcinoma (SCC), and large-cell carcinoma. Adenocarcinoma and squamous carcinoma subtypes represent over $85 \%$ of NSCLC cases. Whereas these NSCLC subtypes exhibit distinct clinical and pathological characteristics, the treatment approaches have remained generic and largely ineffective despite advances in cytotoxic drugs, radiotherapy, and clinical management. The cure rate for advanced NSCLC remains among the most dis$\mathrm{mal}$ in oncology. For all stages of NSCLC, the 5 -year survival rate has remained fixed at $15 \%$ for the last 15 years. The recent success of molecularly targeted therapies for a limited number of cases with specific cancer genotypes (Lynch et al. 2004; Paez et al. 2004) has solidified the view that a more detailed knowledge of the spectrum of genetic lesions in lung cancer will in turn lead to meaningful therapeutic progress.

To date, the majority of lung cancer genetic studies have cataloged mutations or promoter methylation status of known cancer genes, performed genome-wide loss-ofheterozygosity $(\mathrm{LOH})$ surveys, and applied comparative genomic hybridization (CGH) to audit regional copy number alterations (CNAs) on metaphase chromosomes or small-scale BAC arrays. These concerted efforts have identified a core set of lesions including K-RAS activation mutations and loss-of-function mutations in the p53 and $\mathrm{Rb}$ pathways (Minna et al. 2002). At the same time, the observed high number of recurrent chromosomal aberrations, particularly amplifications and deletions, suggests that only a small fraction of the lung cancer genes has been identified to date.

Integrated $\mathrm{CGH}$ and expression profiling have emerged as a highly effective approach to cancer gene discovery, capable of providing a genome-wide view of the regional gains and losses throughout the cancer genome (Kallioniemi et al. 1994) and associated copynumber-driven changes in gene expression (Pollack et al. 1999, 2002; Aguirre et al. 2004). In the case of NSCLC, chromosomal CGH studies have revealed recurrent gains at $1 \mathrm{q} 31,3 \mathrm{q} 25-27,5 \mathrm{p} 13-14$, and $8 \mathrm{q} 23-24$ and deletions at 3p21, 8p22, 9p21-22, 13q22, and 17p12-13 (Petersen et al. 1997; Bjorkqvist et al. 1998a; Luk et al. 2001; Pei et al. 2001; Balsara and Testa 2002). A recent limited array CGH survey of known genes/loci possibly contributing to lung cancer has demonstrated the utility of this approach by confirming recurrent chromosome $3 p$ deletions and $3 q$ gains - and identified PIK3CA as a resident of chromosome 3q amplicon (Massion et al. 2002), a gene shown subsequently to harbor activating point mutations in some lung cancer cases (Samuels et al. 2004).

In the microarray format, the resolution of CGH is dictated by the number and quality of mapped probes positioned along the genome (Albertson and Pinkel 2003). In this study, high-density cDNA- and oligonucleotidebased arrays were used to conduct high-resolution surveys of CNAs present in a well-defined collection of pri- 
mary ACs and SCCs and in a panel of established NSCLC cell lines (Tonon et al. 2005). Zhao et al. (2005) have recently performed a similar analysis on NSCLC and SCLC cell lines and primary tumors, using singlenucleotide polymorphism arrays.

The application of novel custom bioinformatics tools, along with integration of expression profiles and public databases, has yielded a dramatic increase in the number of recurrent amplifications and deletions detectable in the NSCLC genome. The high degree of NSCLC genomic complexity, the recurrent nature of these lesions, and preliminary functional characterization of resident genes point to a large number of relevant oncogenic events, opening potential therapeutic and diagnostic opportunities.

\section{RESULTS}

\section{Identification of Known and Novel CNAs in the NSCLC Genome}

Genome-wide array-CGH (aCGH) profiling was performed on 44 tumors, $18 \mathrm{ACs}$, and $26 \mathrm{SCCs}$, presenting greater than $70 \%$ tumor cellularity. Additionally, 34 NSCLC cell lines were analyzed by CGH (Tonon et al. 2005). Expression profiling was also performed on most of the primary tumors and cell lines analyzed by $\mathrm{CGH}$.

CGH profiles were generated to identify CNAs as described previously (Aguirre et al. 2004). To identify copy number changes above noise background, we applied a modified version of the circular binary segmentation method as described previously (Aguirre et al. 2004; O1shen et al. 2004). The most striking feature of the NSCLC data set was the large number of CNAs $(n=319)$ which, along with the high degree of structural complexity for each CNA, prompted us to filter the data set through an algorithm proven effective in defining and prioritizing CNAs across large, highly complex aCGH data sets (Aguirre et al. 2004). Some of these CNAs were present across different samples, allowing the definition of a minimal common region (MCR) of gain/amplification or loss/deletion. To facilitate the identification of those MCRs that might have strong pathogenetic relevance (referred to as high-priority MCRs), we applied a set of criteria that includes the occurrence in at least one tumor sample and the presence of at least one high-amplitude event $\left(\log _{2} 0.8\right)$ (Tonon et al. 2005). This algorithm yielded 93 so-called "high-confidence" MCRs (Table 1). Seventyfour of these high-priority MCRs were amplifications and 19 were deletions, with a median size of $1.5 \mathrm{Mb}$. Moreover, given that the parameters used by our automated MCR definition program are relatively conservative and that not all genes are represented by probes on these microarrays, real-time quantitative polymerase chain reaction (QPCR) measurement of gene dosage and fluorescence in situ hybridization (FISH) analysis can further refine and narrow the boundaries of an MCR, as illustrated by the 8p12-p11.2 amplicon (see Figs. 5 and 6), thereby presenting a large number of loci with a highly tractable number of candidate cancer genes for further analysis.

On first inspection, the data set contained all the regional gains and losses previously identified in NSCLC by chromosomal $\mathrm{CGH}$ and conventional genomic methods including the known gains at 1q31, 3q25-27, 5p1314 , and $8 \mathrm{q} 23-24$, as well as the known deletions at $3 \mathrm{p} 21$, 8p22, 9p21-22, 13q22, and 17p12-13 (Fig. 1). Furthermore, virtually all of the genes implicated in the patho-

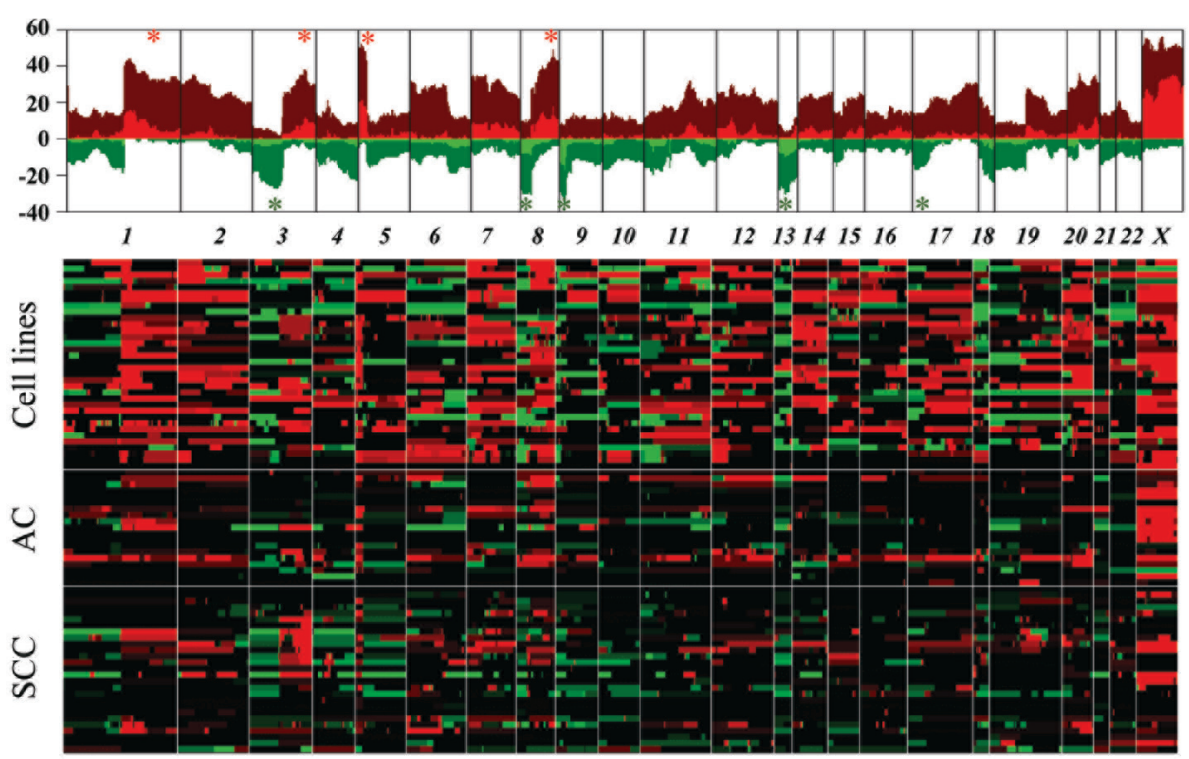

Figure 1. Genomic profiles of primary lung adeno and squamous carcinomas and lung cancer cell lines. (Upper panel) Recurrence of chromosomal alterations. Integer-value recurrence of CNAs in segmented data ( $y$ axis) is plotted for each probe evenly aligned along the $x$ axis in chromosome order. Dark red or green bars denote gain or loss of chromosome material, bright red or green bars represent probes within regions of amplification or deletion. Asterisks identify the most frequent region of gains (red) and losses ( $g r e e n)$, as reported previously (Balsara et al. 2002). (Lower panel) Heat map plot showing discrete CNAs within all samples with the $x$ axis representing probes ordered by genomic map positions and the $y$ axis representing individual samples. Red represents chromosomal gain/amplification and green denotes chromosomal loss/deletion. (Reprinted, with permission, from Tonon et al. 2005 [CNational Academy of Sciences].) 
Table 1. High-Confidence MCRs in Lung AC and SCC Primary Tumors and Cell Lines

\begin{tabular}{|c|c|c|c|c|c|c|c|c|c|c|c|}
\hline \multirow[b]{3}{*}{ Cytogenetic band } & \multicolumn{4}{|c|}{ Minimal common regions (MCRs) } & \multicolumn{5}{|c|}{ MCR recurrence } & \multirow{3}{*}{$\begin{array}{l}\text { Cancer-related } \\
\text { genes }\end{array}$} & \multirow[b]{3}{*}{ miRNA } \\
\hline & \multirow{2}{*}{$\begin{array}{l}\text { position } \\
(\mathrm{Mb})\end{array}$} & \multirow{2}{*}{$\begin{array}{l}\text { size } \\
(\mathrm{Mb})\end{array}$} & \multirow{2}{*}{$\begin{array}{c}\max / \min \\
\text { value }\end{array}$} & \multirow{2}{*}{$\begin{array}{c}\# \\
\text { transcripts }\end{array}$} & \multicolumn{3}{|c|}{ gain/loss } & $\underline{\mathrm{amp}}$ & del & & \\
\hline & & & & & $\%$ & $\mathrm{~T}$ & $\bar{C}$ & $\mathrm{~T}$ & $\mathrm{C}$ & & \\
\hline & & Gain an & d amplifice & ation & & & & & & & \\
\hline $1 \mathrm{p} 36.32-1 \mathrm{p} 36.32$ & $2.37-2.47$ & 0.1 & 1.2 & 2 & 22 & 9 & 9 & 3 & 0 & & \\
\hline $1 \mathrm{p} 36.21-1 \mathrm{p} 36.12$ & $15.29-20.69$ & 5.4 & 1.32 & 86 & 20 & 8 & 9 & 1 & 1 & SDHB, PAX7 & \\
\hline $1 \mathrm{p} 34.3-1 \mathrm{p} 34.3$ & $37.82-38.13$ & 0.32 & 2.92 & 11 & 18 & 7 & 8 & 1 & 1 & & \\
\hline 1p34.2-1p34.1 & $41.65-44.9$ & 3.26 & 2.35 & 50 & 19 & 6 & 10 & 3 & 2 & & \\
\hline $1 \mathrm{q} 21.3-1 \mathrm{q} 22$ & $150.95-151.92$ & 0.98 & 1.96 & 29 & 49 & 17 & 24 & 3 & 13 & & \\
\hline $1 \mathrm{q} 31.2-1 \mathrm{q} 32.1$ & $189.28-197.57$ & 8.29 & 1.22 & 35 & 40 & 16 & 17 & 1 & 4 & & $\begin{array}{l}\text { hsa-mir-181b-1, } \\
\text { hsa-mir-213 }\end{array}$ \\
\hline $1 \mathrm{q} 32.2-1 \mathrm{q} 32.2$ & $206.17-206.24$ & 0.06 & 1.05 & 3 & 39 & 15 & 17 & 1 & 4 & & \\
\hline $2 \mathrm{p} 16.3-2 \mathrm{p} 14$ & $49.1-64.73$ & 15.63 & 1.11 & 54 & 40 & 13 & 21 & 1 & 3 & BCL11A, REL & $\begin{array}{l}\text { hsa-mir-217, } \\
\text { hsa-mir-216 }\end{array}$ \\
\hline $2 q 11.2-2 q 11.2$ & $96.68-96.95$ & 0.27 & 2.16 & 8 & 35 & 14 & 16 & 4 & 4 & & \\
\hline $2 \mathrm{q} 14.1-2 \mathrm{q} 14.2$ & $118.58-120.16$ & 1.57 & 0.88 & 11 & 28 & 9 & 14 & 1 & 2 & & \\
\hline $2 \mathrm{q} 31.1-2 \mathrm{q} 31.1$ & $170.19-170.32$ & 0.13 & 1.14 & 4 & 28 & 11 & 13 & 1 & 1 & & \\
\hline $3 \mathrm{p} 12.1-3 \mathrm{p} 11.1$ & $87.07-88.45$ & 1.38 & 1.32 & 8 & 17 & 6 & 8 & 1 & 1 & & \\
\hline $3 q 11.2-3 q 12.3$ & $95.26-103.06$ & 7.8 & 0.82 & 43 & 33 & 15 & 12 & 2 & 1 & TFG & \\
\hline $3 q 21.3-3 q 25.32$ & $130.02-159.3$ & 29.28 & 0.85 & 182 & 45 & 21 & 17 & 6 & 4 & GMPS & \\
\hline $3 q 29-3 q 29$ & 195.34-196.56 & 1.22 & 1.06 & 12 & 36 & 16 & 14 & 6 & 3 & & \\
\hline $4 q 12-4 q 12$ & $53.58-55$ & 1.42 & 1.47 & 6 & 22 & 9 & 10 & 1 & 4 & FIP1L1, CHIC2 & \\
\hline $4 q 13.3-4 q 13.3$ & $75.33-76.03$ & 0.7 & 0.92 & 6 & 17 & 7 & 7 & 2 & 1 & & \\
\hline $4 q 21.1-4 q 21.1$ & 77.09-78.06 & 0.97 & 0.85 & 13 & 14 & 5 & 7 & 1 & 1 & & \\
\hline $5 p 15.33-5 p 15.33$ & $0.53-0.92$ & 0.38 & 2.67 & 5 & 60 & 27 & 24 & 6 & 15 & & \\
\hline $5 \mathrm{p} 12-5 \mathrm{p} 12$ & $42.76-43.48$ & 0.73 & 2.69 & 9 & 52 & 23 & 20 & 3 & 13 & & \\
\hline $5 q 31.3-5 q 31.3$ & $140.55-140.66$ & 0.12 & 1.99 & 11 & 19 & 6 & 10 & 2 & 4 & & \\
\hline $6 \mathrm{p} 25.2-6 \mathrm{p} 24.3$ & $2.96-8.04$ & 5.09 & 1.59 & 33 & 39 & 16 & 16 & 2 & 2 & & \\
\hline $6 \mathrm{p} 22.3-6 \mathrm{p} 22.3$ & $17.87-20.56$ & 2.69 & 1.59 & 9 & 36 & 15 & 15 & 2 & 3 & DEK & \\
\hline $6 \mathrm{p} 22.1-6 \mathrm{p} 22.1$ & $27.95-28.47$ & 0.52 & 0.91 & 24 & 33 & 13 & 14 & 1 & 1 & & \\
\hline $6 \mathrm{p} 12.3-6 \mathrm{p} 12.2$ & $49.91-52.16$ & 2.25 & 1.21 & 6 & 35 & 13 & 16 & 2 & 2 & & $\begin{array}{l}\text { hsa-mir-206, } \\
\text { hsa-mir-133b }\end{array}$ \\
\hline $6 \mathrm{p} 12.1-6 \mathrm{p} 12.1$ & $53.47-55.73$ & 2.26 & 1.21 & 11 & 35 & 13 & 16 & 3 & 2 & & \\
\hline $6 \mathrm{q} 24.3-6 \mathrm{q} 25.1$ & $145.99-149.77$ & 3.79 & 1.16 & 11 & 17 & 6 & 8 & 2 & 1 & & \\
\hline $6 \mathrm{q} 25.2-6 \mathrm{q} 25.2$ & $153.38-154.67$ & 1.28 & 1.68 & 5 & 16 & 5 & 8 & 1 & 1 & & \\
\hline $7 \mathrm{p} 11.2-7 \mathrm{p} 11.2$ & $54.41-55.94$ & 1.53 & 3.62 & 15 & 36 & 13 & 18 & 2 & 7 & EGFR & \\
\hline $7 \mathrm{q} 21.3-7 \mathrm{q} 21.3$ & $93.2-95.37 \diamond$ & 2.17 & 1.96 & 13 & 40 & 11 & 22 & 2 & 7 & & \\
\hline $7 \mathrm{q} 21.3-7 \mathrm{q} 22.1$ & $97.13-98.66$ & 1.54 & 1.96 & 17 & 40 & 10 & 23 & 2 & 7 & & \\
\hline $7 q 31.2-7 q 31.2$ & $115.22-116.9$ & 1.68 & 2.15 & 10 & 34 & 10 & 18 & 2 & 7 & MET & \\
\hline 8p12-8p11.22* & $38.24-38.45 *$ & 0.21 & 1.98 & 2 & 35 & 17 & 12 & 6 & 4 & $\begin{array}{l}\text { WHSC1L1, } \\
\text { FGFR1 }\end{array}$ & \\
\hline $8 \mathrm{q} 11.21-8 \mathrm{q} 22.1$ & $48.86-97.23 \bullet$ & 48.37 & 1.42 & 192 & 52 & 19 & 24 & 5 & 11 & $\begin{array}{l}\text { NCOA2, NBS1, } \\
\text { CBFA2T1 }\end{array}$ & , hsa-mir-124a-2 \\
\hline $8 \mathrm{q} 24.13-8 \mathrm{q} 24.13$ & $123.37-126.14$ & 2.76 & 0.9 & 23 & 54 & 21 & 24 & 4 & 9 & & \\
\hline $8 \mathrm{q} 24.21-8 \mathrm{q} 24.21$ & $128.5-129.02$ & 0.52 & 4.36 & 3 & 59 & 22 & 27 & 4 & 14 & MYC & \\
\hline $8 \mathrm{q} 24.3-8 \mathrm{q} 24.3$ & $145.67-146.25$ & 0.58 & 0.81 & 21 & 52 & 20 & 23 & 4 & 8 & RECQL4 & \\
\hline $10 \mathrm{q} 24.1-10 \mathrm{q} 24.1$ & $97.62-98.11$ & 0.49 & 1.15 & 8 & 16 & 3 & 10 & 1 & 1 & & \\
\hline $10 \mathrm{q} 26.3-10 \mathrm{q} 26.3$ & $135.24-135.24$ & 0.01 & 1.28 & 1 & 11 & 1 & 8 & 1 & 3 & & \\
\hline $11 \mathrm{p} 14.2-11 \mathrm{p} 14.1$ & $26.54-28$ & 1.46 & 0.95 & 13 & 20 & 7 & 10 & 1 & 1 & & \\
\hline $11 \mathrm{p} 13-11 \mathrm{p} 13$ & $31.76-34.08$ & 2.32 & 2.84 & 21 & 23 & 9 & 10 & 1 & 1 & WT1, LMO2 & \\
\hline $11 \mathrm{q} 13.3-11 \mathrm{q} 13.3$ & 69.3-69.99 & 0.69 & 3.46 & 8 & 37 & 11 & 21 & 3 & 6 & & \\
\hline $11 \mathrm{q} 22.1-11 \mathrm{q} 22.2$ & $99.73-102.15$ & 2.41 & 0.94 & 16 & 27 & 9 & 13 & 1 & 3 & BIRC3 & \\
\hline $12 \mathrm{p} 13.33-12 \mathrm{p} 13.33$ & $0.17-0.81$ & 0.64 & 1.09 & 7 & 36 & 12 & 18 & 1 & 6 & & \\
\hline $12 \mathrm{p} 13.2-12 \mathrm{p} 12.3$ & $12.37-16.6$ & 4.22 & 1.16 & 39 & 29 & 11 & 13 & 2 & 5 & & \\
\hline $12 \mathrm{p} 12.1-12 \mathrm{p} 11.23$ & 24.61-26.95 & 2.34 & 1.98 & 13 & 37 & 15 & 16 & 5 & 7 & KRAS2 & \\
\hline $12 \mathrm{q} 12-12 \mathrm{q} 13.11$ & $43.74-46.42$ & 2.68 & 2.68 & 14 & 31 & 11 & 15 & 2 & 6 & & \\
\hline $12 q 13.2-12 q 13.2$ & $54.72-54.84$ & 0.12 & 1.4 & 8 & 29 & 10 & 14 & 2 & 2 & ERBB3 & \\
\hline $12 \mathrm{q} 15-12 \mathrm{q} 15$ & $67.42-67.95$ & 0.53 & 1.82 & 5 & 34 & 14 & 14 & 5 & 4 & & \\
\hline $13 q 32.1-13 q 32.1$ & $94.07-95.21$ & 1.14 & 1.03 & 6 & 6 & 3 & 2 & 1 & 1 & & \\
\hline $13 q 34-13 q 34$ & $111.77-112.97 \bullet$ & 1.2 & 1.21 & 16 & 14 & 4 & 8 & 2 & 5 & & \\
\hline $13 q 34-13 q 34$ & $113.25-114.11$ & 0.86 & 1.12 & 10 & 14 & 4 & 8 & 1 & 5 & & \\
\hline $14 q 13.2-14 q 13.3$ & $34.64-36.22$ & 1.58 & 2.23 & 20 & 29 & 9 & 15 & 2 & 4 & & \\
\hline $14 \mathrm{q} 22.2-14 \mathrm{q} 22.3$ & $53.49-55.15$ & 1.66 & 1.41 & 22 & 30 & 8 & 17 & 1 & 6 & & \\
\hline $14 \mathrm{q} 32.13-14 \mathrm{q} 32.13$ & $93.66-94.03$ & 0.37 & 1.1 & 9 & 29 & 6 & 18 & 1 & 4 & & \\
\hline $15 q 25.2-15 q 25.3$ & $82.35-83.48$ & 1.13 & 0.95 & 22 & 31 & 10 & 16 & 2 & 5 & & \\
\hline $16 \mathrm{p} 12.1-16 \mathrm{p} 12.1$ & $23.68-27.37$ & 3.69 & 0.89 & 21 & 18 & 6 & 9 & 1 & 2 & & \\
\hline $16 \mathrm{q} 12.1-16 \mathrm{q} 12.2$ & $51.03-52.87$ & 1.84 & 1.3 & 9 & 20 & 7 & 10 & 1 & 4 & & \\
\hline $16 \mathrm{q} 22.2-16 \mathrm{q} 22.2$ & $69.62-69.87$ & 0.26 & 1.08 & 2 & 18 & 6 & 9 & 1 & 4 & & \\
\hline 16q24.2-16q24.3 & $86.43-87.23$ & 0.81 & 1.7 & 9 & 18 & 5 & 10 & 2 & 3 & & \\
\hline $17 \mathrm{p} 11.2-17 \mathrm{p} 11.2$ & $17.09-18.86$ & 1.77 & 0.84 & 40 & 20 & 7 & 10 & 1 & 1 & & \\
\hline $18 \mathrm{p} 11.32-18 \mathrm{p} 11.32$ & $0.2-0.9$ & 0.7 & 1.7 & 9 & 25 & 13 & 9 & 4 & 1 & & \\
\hline
\end{tabular}


TONON ET AL.

Table 1. High-Confidence MCRs in Lung AC and SCC Primary Tumors and Cell Lines (Continued)

\begin{tabular}{|c|c|c|c|c|c|c|c|c|c|c|c|}
\hline \multirow[b]{3}{*}{ Cytogenetic band } & \multicolumn{4}{|c|}{ Minimal common regions (MCRs) } & \multicolumn{5}{|c|}{ MCR recurrence } & \multirow{3}{*}{$\begin{array}{l}\text { Cancer-related } \\
\text { genes }\end{array}$} & \multirow[b]{3}{*}{ miRNA } \\
\hline & \multirow{2}{*}{$\begin{array}{l}\text { position } \\
(\mathrm{Mb})\end{array}$} & \multirow{2}{*}{$\begin{array}{l}\text { size } \\
(\mathrm{Mb})\end{array}$} & \multirow{2}{*}{$\begin{array}{c}\text { max/min } \\
\text { value }\end{array}$} & \multirow{2}{*}{$\begin{array}{c}\# \\
\text { transcripts }\end{array}$} & \multicolumn{3}{|c|}{ gain/loss } & \multicolumn{2}{|c|}{ amp/del } & & \\
\hline & & & & & $\%$ & $\mathrm{~T}$ & $\mathrm{C}$ & $\overline{\mathrm{T}}$ & $\mathrm{C}$ & & \\
\hline $18 \mathrm{q} 11.2-18 \mathrm{q} 11.2$ & $18.25-20.9$ & 2.65 & 0.96 & 15 & 20 & 8 & 9 & 2 & 0 & & \multirow{11}{*}{$\begin{array}{l}\text { hsa-mir-99a, } \\
\text { hsa-let-7c, } \\
\text { hsa-mir-125b-2 }\end{array}$} \\
\hline $18 \mathrm{q} 12.1-18 \mathrm{q} 12.1$ & $26.83-27.31$ & 0.48 & 1.55 & 6 & 19 & 9 & 7 & 2 & 1 & & \\
\hline $18 q 12.3-18 q 21.1$ & $37.92-46.03$ & 8.12 & 1.41 & 33 & 23 & 11 & 8 & 1 & 1 & & \\
\hline $19 \mathrm{p} 13.12-19 \mathrm{p} 13.12$ & $14.8-16.01$ & 1.22 & 1.53 & 39 & 11 & 5 & 4 & 1 & 1 & BRD4 & \\
\hline $19 q 12-19 q 12$ & $35.01-35.73$ & 0.73 & 1.91 & 4 & 31 & 13 & 13 & 2 & 5 & & \\
\hline $19 q 13.33-19 q 13.33$ & $55.52-55.68$ & 0.16 & 1.01 & 8 & 17 & 5 & 9 & 1 & 1 & & \\
\hline 20p12.3-20p12.2 & 7.91-10.57 & 2.66 & 0.85 & 12 & 31 & 13 & 14 & 1 & 3 & & \\
\hline $20 q 11.21-20 q 11.21$ & 29.66-29.88 & 0.22 & 3.85 & 5 & 42 & 13 & 23 & 1 & 8 & & \\
\hline $20 q 13.32-20 q 13.33$ & $57.04-60.21$ & 3.17 & 1.61 & 19 & 41 & 12 & 23 & 1 & 11 & SS18L1 & \\
\hline $21 \mathrm{q} 11.2-21 \mathrm{q} 21.1$ & $14.52-18.56$ & 4.04 & 1.14 & 13 & 17 & 7 & 7 & 2 & 0 & & \\
\hline \multirow[t]{2}{*}{$22 \mathrm{q} 11.21-22 \mathrm{q} 11.21$} & $19.09-20.3$ & 1.22 & 1.02 & 28 & 25 & 11 & 10 & 1 & 3 & & \\
\hline & \multicolumn{4}{|c|}{ Loss and deletion } & & & & & & & \\
\hline 1p22.1-1p22.1 & 92.45-94.07 & 1.62 & -0.89 & 15 & 18 & 9 & 7 & 1 & 1 & & \\
\hline $2 q 34-2 q 35$ & $209.15-217.17$ & 8.02 & -0.83 & 25 & 11 & 6 & 3 & 1 & 1 & ATIC & \\
\hline $2 \mathrm{q} 36.1-2 \mathrm{q} 37.1$ & $223.74-230.87$ & 7.12 & -1.03 & 28 & 8 & 5 & 2 & 1 & 1 & & \\
\hline $3 \mathrm{p} 26.3-3 \mathrm{p} 26.2$ & $0.43-3.09$ & 2.66 & -0.87 & 4 & 23 & 11 & 9 & 1 & 3 & & \\
\hline $3 \mathrm{p} 11.2-3 \mathrm{p} 11.1$ & $87.39-88.45$ & 1.07 & -0.92 & 6 & 24 & 14 & 7 & 3 & 1 & & \\
\hline $4 p 15.32-4 p 15.32$ & $15.84-17.48$ & 1.64 & -0.88 & 8 & 14 & 8 & 5 & 2 & 0 & & \\
\hline $6 \mathrm{p} 21.32-6 \mathrm{p} 21.32$ & $32.47-33.01$ & 0.54 & -1.05 & 17 & 11 & 3 & 6 & 2 & 1 & & \\
\hline $6 q 21-6 q 22.33$ & 111.4-128.94 & 17.55 & -1 & 72 & 23 & 8 & 11 & 1 & 4 & & \\
\hline $7 \mathrm{p} 22.3-7 \mathrm{p} 22.3$ & $1.36-2.05$ & 0.69 & -1.21 & 7 & 10 & 5 & 3 & 1 & 1 & & \\
\hline $7 q 34-7 q 34$ & $142.28-142.44$ & 0.16 & -1.39 & 4 & 13 & 7 & 4 & 2 & 1 & & \\
\hline $8 \mathrm{p} 21.1-8 \mathrm{p} 12$ & $28.74-33.48$ & 4.74 & -1.28 & 22 & 36 & 15 & 16 & 1 & 8 & WRN & \\
\hline $9 p 21.3-9 p 21.3$ & $21.47-22$ & 0.53 & -4.81 & 4 & 43 & 16 & 21 & 1 & 18 & CDKN2A & hsa-mir-31 \\
\hline $11 \mathrm{q} 11-11 \mathrm{q} 11^{\wedge}$ & $55.1-55.18^{\wedge}$ & 0.08 & -4.06 & 2 & 23 & 13 & 6 & 7 & 1 & & \\
\hline $11 \mathrm{q} 24.3-11 \mathrm{q} 24.3$ & $128.13-129.24$ & 1.11 & -0.84 & 9 & 16 & 5 & 8 & 1 & 4 & & \\
\hline $12 q 12-12 q 13.11$ & $42.41-44.87 \bullet$ & 2.46 & -1.94 & 13 & 7 & 2 & 4 & 1 & 2 & & \\
\hline $13 q 12.11-13 q 12.11$ & 19.14-19.56 & 0.41 & -3.51 & 5 & 34 & 14 & 14 & 1 & 7 & & \\
\hline $13 q 14.13-13 q 21.1$ & $45.82-57.2$ & 11.38 & -1.35 & 60 & 35 & 16 & 13 & 1 & 8 & RB1 & $\begin{array}{l}\text { hsa-mir-16-1, } \\
\text { hsa-mir-15a }\end{array}$ \\
\hline $13 q 32.2-13 q 32.2$ & $97.47-97.9$ & 0.42 & -3.25 & 3 & 29 & 13 & 11 & 1 & 8 & & \\
\hline $18 \mathrm{q} 21.33-18 \mathrm{q} 22.2$ & $58.4-65.82$ & 7.43 & -1.26 & 26 & 29 & 10 & 14 & 1 & 5 & & \\
\hline 21p11.2-21p11.1 & 9.93-10.08 & 0.15 & -1.33 & 3 & 17 & 9 & 6 & 1 & 1 & & \\
\hline
\end{tabular}

The numbers of primary tumors (T) or cell lines (C) with gain or loss, and amplification or deletion, are listed, respectively. For other definitions, see text and Tonon et al. (2005). MCR recurrence is denoted as percentage of the total data set. In bold, the MCRs verified by RT-PCR and FISH (Figs. 5 and 6; data not shown). Number of transcripts is based on build 35, NCBI. Only the known genes within the boundaries have been included. The list of cancer-related genes was derived from Futreal et al. (2004). The short arm of chromosome 3 was consistently lost across several primary tumors and cell lines (Figs. 1 and 2). Three smaller regions within the short arm of chromosome 3 were identified by the automated locus definition program, based on the presence and recurrence of deletions in a subset of samples (Fig. 2, bright green bars). (Reprinted, with permission, from Tonon et al. 2005 [@National Academy of Sciences].)

( ) High-priority MCRs that are common with the PDAC data set (Aguirre et al. 2004).

(*) MCR in 8p, which was subject to further fine mapping (Figs. 5 and 6 , and see text).

(^) The MCR at 11q11 has recently been shown by Sebat et al. (2004) to be a copy number polymorphism (ORF5I1, chromosome 11q11).

genesis of NSCLC were contained within the high-confidence MCRs, including $\mathrm{p} 16^{\mathrm{INK} 4 \mathrm{~A}}$ and RB1 tumor suppressor genes and MYC, EGFR, and KRAS2 oncogenes (Table 1). Additionally, most of the altered regions identified in a recent study using single-nucleotide polymorphism arrays on NSCLC and SCLC samples (Zhao et al. 2005) were included among the high-confidence MCRs in the present study.

The whole short arm of chromosome 3 was consistently lost, as described previously (Zabarovsky et al. 2002; Protopopov et al. 2003; Kashuba et al. 2004), with a peak recurrence at around $50 \mathrm{Mb}$, corresponding to 3p21.1 (29 of 79 samples, 36\%). Segmentation did not identify obvious homozygous deletions that would point to a specific target in this recurrently deleted region of $3 p$; however, this region contains RASSF1, TUSC2,
SEMA3B, HYAL2, and FHIT, genes that have shown LOH in NSCLC (Figs. 1 and 2) (Lerman and Minna 2000; Balsara and Testa 2002; Danilkovitch-Miagkova et al. 2003; Imreh et al. 2003).

The most notable feature of the high-priority MCR data set was a subset (21 of 93) of highly focal MCRs that spanned less than $0.5 \mathrm{Mb}$ with a median number of only 5 genes (Table 2). From a total of 120 genes (of 139 genes in these $0.5-\mathrm{Mb} \mathrm{MCRs})$ represented on the Affymetrix Plus 2.0 microarray platform, $53(\sim 40 \%)$ demonstrated copy-number-driven expression. Among this subset of genes, some already have an established role in cancer (e.g., ERBB3) or are homologous to known cancer genes (a PTEN-related molecule that is in a region of deletion). Additionally, three members of the cyclin family were present in two different MCRs (cyclin M3, M4, and cy- 


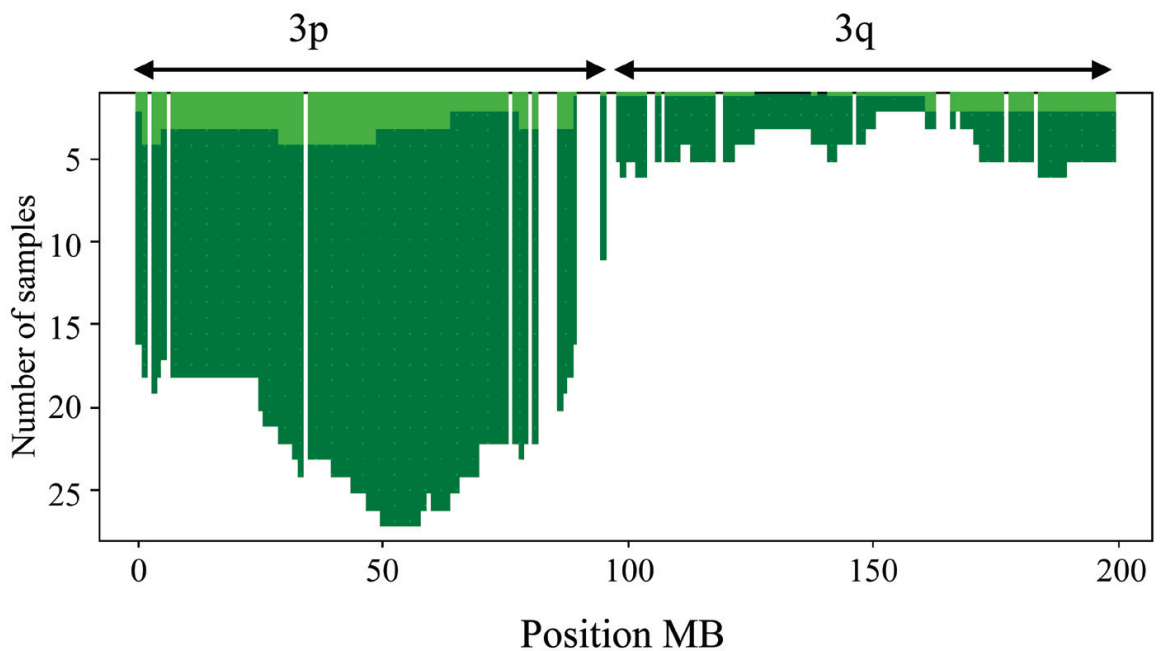

Figure 2. Recurrence of chromosome 3 alterations. Integer-value recurrence of CNAs in segmented data ( $y$ axis) is plotted for each probe aligned along the $x$ axis in chromosome order. Dark green bars denote loss of chromosome material, bright green bars represent probes within regions of deletion. White spaces represent gaps between probes. (Reprinted, with permission, from Tonon et al. 2005 [CNational Academy of Sciences].)

Table 2. High-Confidence MCRs in Lung ACs and SCCs, Spanning Less Than 0.5 Mb

\begin{tabular}{|c|c|c|c|c|c|c|c|c|c|c|}
\hline \multirow[b]{3}{*}{ Cytogenetic band } & \multicolumn{4}{|c|}{ Minimal common regions (MCRs) } & \multicolumn{5}{|c|}{ MCR recurrence } & \multirow[b]{3}{*}{ Candidates } \\
\hline & \multirow{2}{*}{$\begin{array}{l}\text { position } \\
(\mathrm{Mb})\end{array}$} & \multirow{2}{*}{$\begin{array}{l}\text { size } \\
(\mathrm{Mb})\end{array}$} & \multirow{2}{*}{$\begin{array}{l}\max / \min \\
\text { value }\end{array}$} & \multirow{2}{*}{$\begin{array}{c}\# \\
\text { transcripts }\end{array}$} & \multicolumn{3}{|c|}{ gain/loss } & \multicolumn{2}{|c|}{ amp/del } & \\
\hline & & & & & $\%$ & $\mathrm{~T}$ & $\mathrm{C}$ & $\mathrm{T}$ & $\mathrm{C}$ & \\
\hline \multicolumn{11}{|c|}{ Gains/amplification } \\
\hline $1 \mathrm{p} 36.32-1 \mathrm{p} 36.32$ & $2.37-2.47$ & 0.10 & 2.92 & 2 & 22 & 9 & 9 & 3 & 0 & PEX10, RER1 \\
\hline 1p34.3-1p34.3 & $37.82-38.13$ & 0.32 & 2.16 & 11 & 18 & 7 & 8 & 1 & 1 & $\begin{array}{l}\text { FLJ31434, YRDC, } \\
\text { FLJ45459 }\end{array}$ \\
\hline $1 \mathrm{q} 32.2-1 \mathrm{q} 32.2$ & $206.17-206.24$ & 0.06 & 1.14 & 3 & 39 & 15 & 17 & 1 & 4 & LAMB3 \\
\hline $2 \mathrm{q} 11.2-2 \mathrm{q} 11.2$ & $96.68-96.95$ & 0.27 & 1.39 & 8 & 35 & 14 & 16 & 4 & 4 & $\begin{array}{l}\text { CNNM3, CNNM4, } \\
\text { SEMA4C }\end{array}$ \\
\hline $2 \mathrm{q} 31.1-2 \mathrm{q} 31.1$ & $170.19-170.32$ & 0.13 & 2.67 & 4 & 28 & 11 & 13 & 1 & 1 & PPIG \\
\hline $5 p 15.33-5 p 15.33$ & $0.53-0.92$ & 0.38 & 1.99 & 5 & 60 & 27 & 24 & 6 & 15 & BRD9 \\
\hline $5 q 31.3-5 q 31.3$ & $140.55-140.66$ & 0.12 & 1.59 & 11 & 19 & 6 & 10 & 2 & 4 & $\begin{array}{c}\text { PCDHB11, } \\
\text { PCDHB12, } \\
\text { PCDHB13 }\end{array}$ \\
\hline 8p12-8p11.22* & 38.24-38.45* & 0.21 & 1.98 & 2 & 35 & 17 & 12 & 6 & 4 & $\begin{array}{l}\text { FGFR1, } \\
\text { WHSC1L1, } \\
\text { LETM2 }\end{array}$ \\
\hline $10 \mathrm{q} 24.1-10 \mathrm{q} 24.1$ & $97.62-98.11$ & 0.49 & 1.96 & 8 & 16 & 3 & 10 & 1 & 1 & CCNJ \\
\hline $10 \mathrm{q} 26.3-10 \mathrm{q} 26.3$ & 135.24-135.24 & 0.01 & 1.04 & 1 & 11 & 1 & 8 & 1 & 3 & C10orf94 \\
\hline $12 q 13.2-12 q 13.2$ & $54.72-54.84$ & 0.12 & 1.98 & 8 & 29 & 10 & 14 & 2 & 2 & ERBB3 \\
\hline $14 \mathrm{q} 32.13-14 \mathrm{q} 32.13$ & $93.66-94.03$ & 0.37 & 1.15 & 9 & 29 & 6 & 18 & 1 & 4 & KIAA1622 \\
\hline $16 \mathrm{q} 22.2-16 \mathrm{q} 22.2$ & $69.62-69.87$ & 0.26 & 1.4 & 2 & 18 & 6 & 9 & 1 & 4 & Hs. 368781 \\
\hline 18q12.1-18q12.1 & $26.83-27.31$ & 0.48 & 1.1 & 6 & 19 & 9 & 7 & 2 & 1 & $\begin{array}{l}\text { DSC1, DSC2, } \\
\text { DSG2 }\end{array}$ \\
\hline $19 q 13.33-19 q 13.33$ & $55.52-55.68$ & 0.16 & 0.73 & 8 & 17 & 5 & 9 & 1 & 1 & SPIB \\
\hline 20q11.21-20q11.21 & 29.66-29.88 & 0.22 & 1.08 & $\begin{array}{c}5 \\
\text { Loss /deletion }\end{array}$ & 42 & 13 & 23 & 1 & 8 & BCL2L1, TPX2 \\
\hline $7 q 34-7 q 34$ & $142.28-142.44$ & 0.16 & -1.39 & 4 & 13 & 7 & 4 & 2 & 1 & LOC 154761 \\
\hline $11 \mathrm{q} 11-11 \mathrm{q} 11^{\wedge}$ & $55.1-55.18$ & 0.08 & -4.06 & 6 & 23 & 13 & 6 & 7 & 1 & 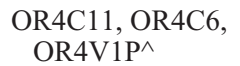 \\
\hline $13 q 12.11-13 q 12.11$ & 19.14-19.56 & 0.41 & -3.51 & 2 & 34 & 14 & 14 & 1 & 7 & HSMPP8, PSPC1 \\
\hline $13 q 32.2-13 q 32.2$ & $97.47-97.9$ & 0.42 & -3.25 & 6 & 29 & 13 & 11 & 1 & 8 & FARP1 \\
\hline 21p11.2-21p11.1 & $9.93-10.08$ & 0.15 & -1.33 & 5 & 17 & 9 & 6 & 1 & 1 & TPTE \\
\hline
\end{tabular}

The numbers of primary tumors (T) or cell lines (C) with gain or loss, and amplification or deletion, are listed, respectively. See text for other definitions. MCR recurrence is denoted as percentage of the total data set. Number of transcripts is based on build 35, NCBI. Only the known genes within the boundaries have been included. In bold the MCRs verified by RT-PCR and/or FISH (Figs. 5 and 6; data not shown). The genes listed are among the subset of genes within the MCRs showing copy-number-driven expression in the Affymetrix 2.0 Plus. (Reprinted, with permission, from Tonon et al. 2005 [@National Academy of Sciences].)

(*) MCR in 8p, which was subject to further fine mapping (see text).

(^) The MCR at 11q11 has recently been shown by Sebat et al. (2004) to be a copy number polymorphism (ORF5I1, chromosome 11q11). 
clin J), and BRD9, a bromodomain gene with potential functional relatedness to BRD4, a gene located within the high-priority MCRs and involved in virus-induced cellular transformation (Table 1; and see Discussion), was also present in one highly focal MCR. These findings highlight the potential for focused and high-yield cancer gene discovery.

Several of the known microRNAs were located within the MCRs (Table 1). The role of microRNA in cancer has been recently established, and the presence of miRNAs within MCRs will require additional study to see whether these genetic elements participate in the development of these lung cancers (Calin et al. 2004a,b; Metzler et al. 2004; He et al. 2005; Lu et al. 2005; O’Donnell et al. 2005).

\section{Common and Distinct Genomic Features in $\mathrm{AC}$ and $\mathrm{SCC}$}

Next, we sought to determine the common and distinguishing features of the AC and SCC subtypes on the genome level. A comparison of overall copy number variation across the genomes of AC and SCC subtypes revealed a higher degree of genomic complexity in the SCC subtype (Fig. 3). Here, complexity is inferred from the number and size of copy number aberrations detected by an objective change-point or segmentation analysis (O1shen et al. 2004). In this analysis, each contiguous genomic region of uniform copy number is delineated as a segment: Each segment contains a copy number different from its neighboring segments. Borders between adjacent segments mark transition in copy number. The number of segments and the size of these segments are indicators of frequency of CNA across the genome. By comparing the incidences of segmentation within each profile, it is clear that the SCC subtype harbors higher overall segment numbers, particularly of the smaller segment sizes (Fig. 3).

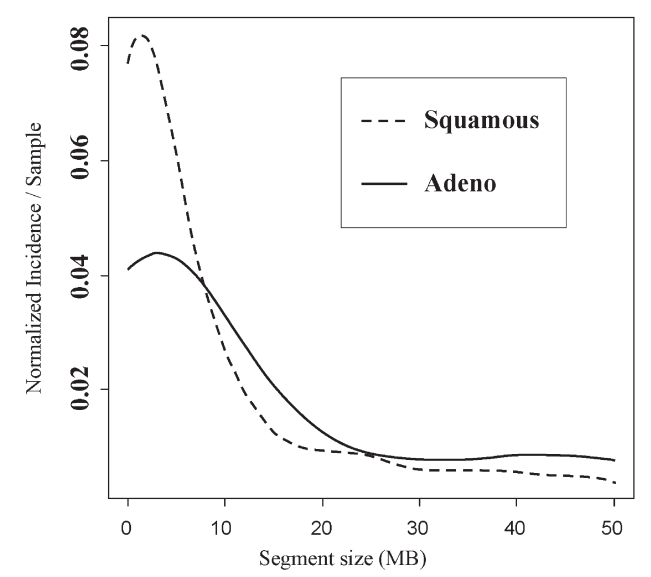

Figure 3. Chromosomal segment length distribution. The incidence of segmentation per sample ( $y$ axis) is shown as a function of segment size ( $x$ axis) for squamous (dashed line) and adenocarcinoma (solid line) samples. Only aberrations of Log2 ratio greater than +0.4 or less than -0.4 are counted. Because segment boundaries are determined by discrete changes in copy number, the number and length of segments within a sample profile are indices of copy number aberration and thus genomic disruption. Note that squamous cell carcinoma samples show a higher incidence of CNA, particularly events less than $2.5 \mathrm{Mb}$.
Taking a global view of the profiles, however, the comparison of overall copy number variation for high-intensity events across the genomes of these two subtypes revealed near complete overlap, including gains/amplifications at $1 \mathrm{q}, 5 \mathrm{p}$, and $20 \mathrm{q}$ and losses/deletions at $3 \mathrm{p}$ and $9 \mathrm{p}$ (data not shown). Previous reports using chromosomal CGH and low-resolution array CGH BAC arrays have suggested that the only genomic aberration consistently differentiating SCC from the AC subtype is $3 \mathrm{q}$ gain/amplification (Petersen et al. 1997; Bjorkqvist et al. 1998b; Luk et al. 2001; Pei et al. 2001; Balsara and Testa 2002; Massion et al. 2002). We reasoned that with our higher-resolution platform capable of detecting previously unrecognized focal CNAs we might be able to determine whether there exist additional genomic events that are characteristic of either SCC or AC. To determine whether there are recurrent regional gains/amplifications or losses/deletions that might be distinct between these subtypes, the incidence of events in each primary tumor group was compared and significance was estimated by permutation test (Tonon et al. 2005). There were no genomic losses/deletions that could differentiate AC and SCC subtypes. Similarly, there were no gains/amplifications that were unique for the AC subtype. However, one region of gain/amplification on the long arm of chromosome 3, from $180 \mathrm{Mb}$ to $199 \mathrm{Mb}$, corresponding to $3 \mathrm{q} 26$ to $3 \mathrm{q} 29$, was significantly targeted in the SSCs (Fig. 4A) - a finding in line with previous reports (Petersen et al. 1997; Bjorkqvist et al. 1998b; Luk et al. 2001; Pei et al. 2001; Balsara and Testa 2002; Massion et al. 2002). Therefore, despite completely distinct histological presentations, SCC and AC are remarkably similar on the genomic level and are likely driven by many of the same oncogenes and tumor suppressor gene mutations.

Given these common and distinct CNA profiles of the NSCLC subsets, we next sought to correlate specific CNAs with expression profile data of the same samples and available expression data sets (Bhattacharjee et al. 2001). In particular, these integrated analyses assessed the extent to which the $3 \mathrm{q}$ might drive the subtype-specific expression patterns. As a corollary, by linked subtype expression patterns and copy number gains, it might be possible to identify subtype diagnostics with more direct linkage to disease pathogenesis. We analyzed the global expression profile data for the same NSCLC samples using SAM (Significant Analysis for Microarray Data; Tusher et al. 2001). A total of 297 probes were significantly different between SCCs and ACs, based on a qvalue (false discovery rate, FDR) cutoff of 0.05 (Storey and Tibshirani 2003). Upon mapping of these genes to their genomic positions, we used a 10-Mb moving-window analysis across the genome and then applied a Fisher's exact test to identify the genomic regions significantly enriched for differentially expressed probes (Tonon et al. 2005). As shown in Figure 4B, this global analysis again identified 3q $180-199 \mathrm{MB}$ as the genomic region whose resident genes were most significantly enriched among the list of differentially expressed genes between AC and SCC. We performed a similar analysis with another recently published lung cancer expression profiling data set (Bhattacharjee et al. 2001), and again, only probes mapping $180-199 \mathrm{MB} 3 \mathrm{q}$ showed a statisti- 
A $\mathrm{aCGH}$

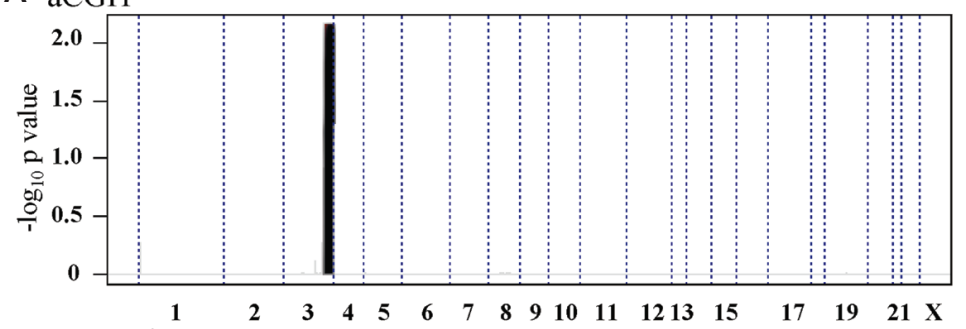

B expression

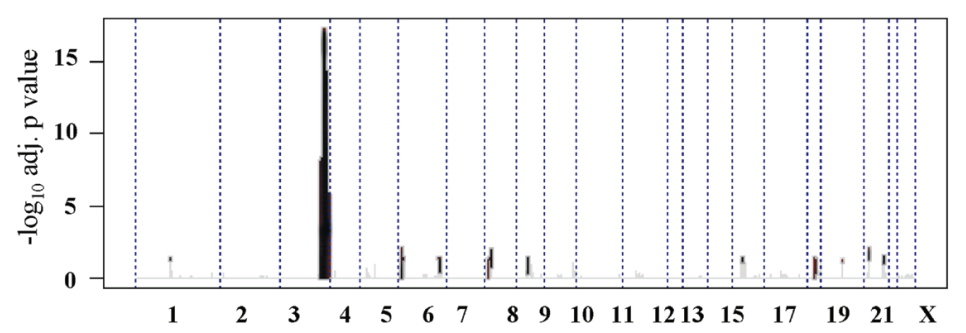

Figure 4. Chromosome 3q, from $180 \mathrm{Mb}$ to 199 $\mathrm{Mb}$, is the only genomic region that shows significant difference between AC and SCC by both aCGH and expression profiling. On both plots, $x$-axis coordinates represent probes ordered by genomic map positions, from chromosome 1 to chromosome X. (A) Probes significantly gained/amplified comparing SCC and $\mathrm{AC}$ primary tumors, on array-CGH. $y$ axis represents the $-\log _{10} p$ value of the permutation test. Probes presenting a $p<0.05$ are plotted in black, probes with a $p>0.05$ in gray. No probes were significantly lost/deleted after comparison between SCC and AC primary tumors. $(B) \mathrm{Ge}-$ nomic regions significantly enriched for differentially expressed probes comparing SCC and AC primary tumors. $y$ axis represents the $-\log _{10}$ adjusted $p$ values of Fisher's exact test for enrichment. Black lines highlight regions with an adjusted $p<0.05$ adjusted for multiple testing, probes with an adjusted $p>0.05$ are in gray. (Reprinted, with permission, from Tonon et al. 2005 [CNational Academy of Sciences].) cally significant enrichment (data not shown). These findings suggest that genes residing within this region on chromosome 3 often show copy-number-driven expression in SCCs.

Gain/amplification of $3 q$ is present in many, but not all, cases of SCC, $54 \%$ in our samples and between $50 \%$ and $85 \%$ in the literature (Petersen et al. 1997; Bjorkqvist et al. 1998b; Luk et al. 2001; Pei et al. 2001; Balsara and Testa 2002; Massion et al. 2002). Given the certain importance of this locus in SCC pathogenesis, we sought to determine whether a subset of probes residing within the $3 \mathrm{q} 180-\mathrm{Mb}$ to $199-\mathrm{Mb}$ region would exhibit robust expression via mechanisms other than gain/amplification consistent with their key role in SCC development. To this end, a one-way ANOVA and a post-hoc Bonferroni test using all the Affymetrix Plus 2.0 probes $(n=166$, corresponding to 106 genes) residing within the $180-\mathrm{Mb}$ to $199-\mathrm{Mb}$ boundaries on $3 \mathrm{q}$ identified a subset of genes showing significant overexpression in SCCs versus ACs, even in the absence of gene copy number gains on $3 q$ in SCCs: p63, Claudin 1, Phosphatidylinositol glycan, class $\mathrm{X}$, and discs large homolog 1 . The p63 gene is most notable, given its seminal role in squamous tissue development and its links to squamous cancer subtypes (Massion et al. 2003; Koster et al. 2004; McKeon 2004; Westfall and Pietenpol 2004). In conclusion, based on the given level of resolution, our integrated aCGH and expression analyses strongly implicate a limited number of genes residing within $3 \mathrm{q}$ as key potential drivers of the SCC histopathological phenotype.

\section{Cross Tumor Type Genomic Comparisons}

The large number of MCRs prompted us to merge the NSCLC data set with another high-resolution pancreatic ductal adenocarcinoma (PDAC) data set (64 MCRs identified in Aguirre et al. 2004) in an effort to identify loci of prime relevance to epithelial carcinogenesis. Comparison of NSCLC and PDAC was motivated by their common epithelial origin, similar clinical aggressiveness, commonality in signature mutations (KRAS, c-Myc, p53, INK4a/ARF, among others), and extreme genomic complexity. As expected, these comparisons identified several loci that are known to be commonly targeted in these cancers including KRAS, c-MYC, and INK4a/ARF loci (data not shown), as well as other novel loci. Among these novel loci were two focal amplicons - one at 8p12p11.2 (position 37.84-39.72) encompassing FGFR1 and another at 20q11 (position 29.66-29.88 MB).

The presence of FGFR1, a cancer-relevant gene not previously implicated in lung cancer, prompted a detailed mapping of the 8p12-p11.2 amplicon. Real-time quantitative PCR (QPCR) and FISH on all eight samples (two cell lines and six primary tumors) confirmed the presence of a high-copy-number amplicon at 8p (Figs. 5 and 6). Based on two informative primary tumor cases, PT3 and PT5, this analysis defined the MCR as $0.14 \mathrm{Mb}$ in size and containing only two annotated genes: WHSC1L1 and LETM2 (Fig. 5A). As QPCR analysis clearly positioned the FGFR1 gene outside of the telomeric boundary of this MCR, and previous studies have implicated FGFR1 as the prime target of $8 \mathrm{p}$ amplicon in other cancer types (Simon et al. 2001; Edwards et al. 2003; Mao et al. 2003), interphase FISH was used to verify the amplicon boundaries in several informative samples. Consistent with QPCR data, FISH with a BAC outside of the MCR and including FGFR1 on PT3 revealed only two copies (Fig. $6 \mathrm{~B})$, providing clear evidence that FGFR1 is not amplified in this sample.

Since CNAs are believed to be one of the mechanisms for altered gene expression, integration of DNA copy number and RNA expression data can serve as an effective early filter for culling bystanders from true targets (Pollack et al. 2002). To this end, we assessed the expression pattern of genes residing within this MCR both by gene expression profiling and by directed RT-QPCR (Fig. 7). The expression patterns of the MCR resident genes (WHSC1L1 and LETM2) and neighboring genes 
A

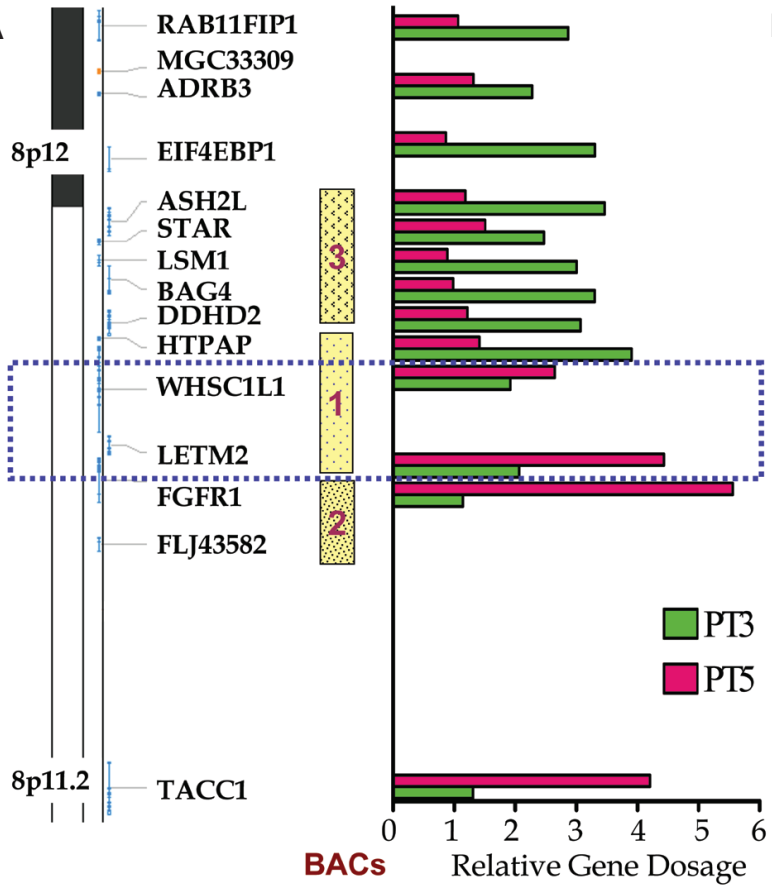

B
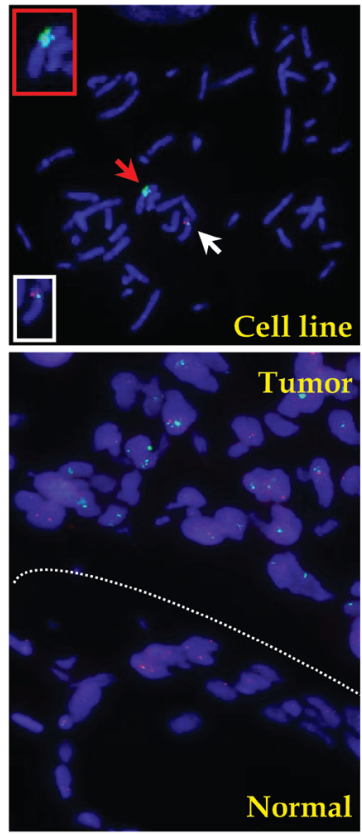

Figure 5. Verification and boundary delimitation of the 8p12-p11.2 amplicon. (A) Real-time PCR verification of the 8p amplicon and its boundaries. Two primary tumors were used to delimit the boundaries, PT3 and PT5. The dotted blue square includes the genes involved in the amplicon. (B) (Upper panel) Metaphase FISH analysis of the cell line NCI-H1703 showing multiple green signals on one derivative chromosome (red arrow and top inset; green signal, BAC\#2). A normal copy of chromosome 8 is also evident (white arrow and bottom inset) showing two signals for BAC\#2 (green) and two signals for the control BAC (RP11-138J2, red signal). (Lower panel) Interphase FISH analysis on a section from the primary tumor PT3, comparing adjacent normal and tumor tissues. Note multiple, highintensity signals with BAC\#1 (green) in the tumor part and single or double signals with BAC\#1 in the normal part of the section. Control BAC, RP11-138J2, red signal. (Reprinted, with permission, from Tonon et al. 2005 [CNational Academy of Sciences].)

A

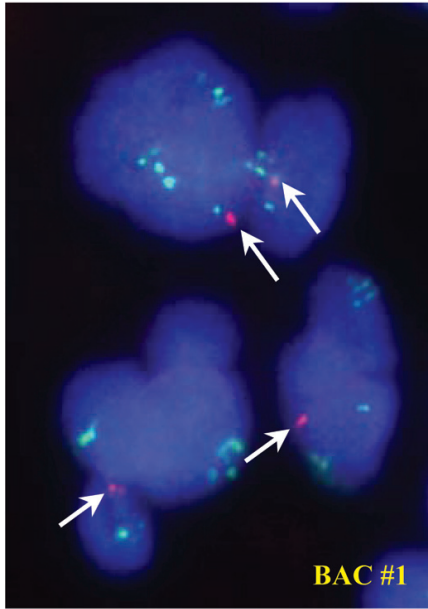

B

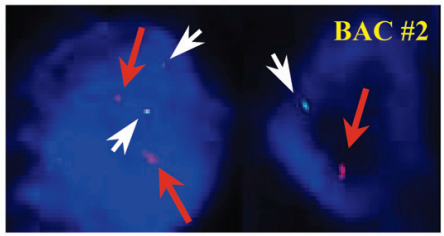

C

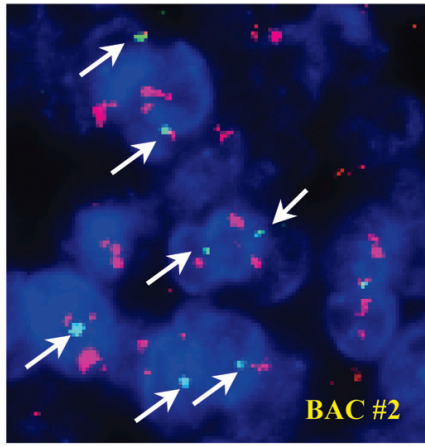

D

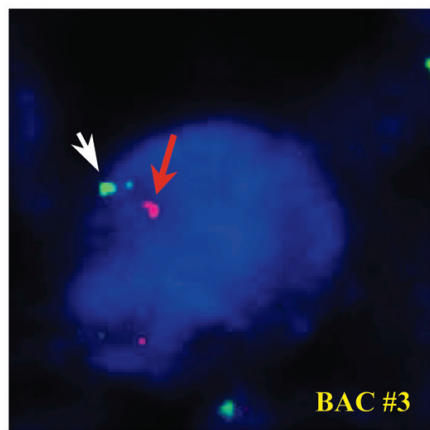

Figure 6. FISH analysis of the $8 \mathrm{p}$ amplicon in a section from the primary tumor PT3 and PT5 to define the boundaries of the amplicon. (A) Interphase FISH analysis on a tissue section from the primary tumor PT3, showing multiple high-intensity signals when using BAC\#1 (green). (White arrow) Control BAC (RP11-138J2, red signal). (B) Interphase FISH analysis on a tissue section from the primary tumor PT3, showing two signals per cell, for both BAC\#2 (red signal, red arrow) and control BAC (RP11-138J2, green signal, white arrow). (C) Interphase FISH analysis on a tissue section from the primary tumor PT5, showing multiple high-intensity signals when using BAC\#2 (red signal). (White arrow) Control BAC (RP11-138J2, green signal). (D) Interphase FISH analysis on a tissue section from the primary tumor PT5, showing two signals per cell, for both BAC\#3 (red signal, red arrow) and control BAC (RP11-138J2, green signal, white arrow). (Reprinted, with permission, from Tonon et al. 2005 [CNational Academy of Sciences].) 


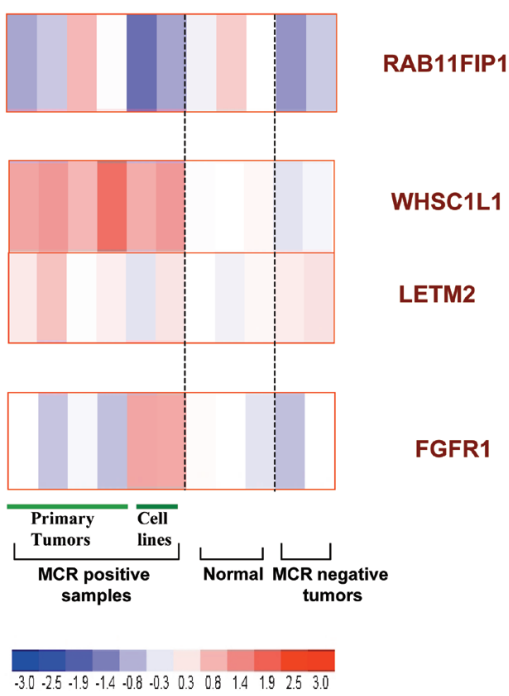

Figure 7. Expression analyses of genes residing in the chromosome $8 p$ amplicon. Heat map representation of the expression level of each of the genes in the amplicon from Affymetrix analysis. When multiple Affymetrix probes for a gene were present, the median value among the probes was used. Each column represents an individual sample, and each row represents a gene. The color intensity on the heat map correlates with the intensity of the expression, red representing overexpression and blue indicating reduced expression. The MCR-positive samples include four of six SCC primary tumors demonstrating the 8p amplicon and NCI-H1703 and NCI-H520, two lung cancer cell lines with the $8 \mathrm{p}$ amplicon. Normal represents three independent normal RNA references, isolated from adjacent histologically normal lung tissues; MCR-negative tumors are two primary tumors not showing amplification at 8p. (Reprinted, with permission, from Tonon et al. 2005 [CNational Academy of Sciences].)

(RAB11FIP1 and FGFR1, positioned external to the telomeric and centromeric boundaries of the MCR, respectively) were assessed. As shown in Figure 7, only WHSC1L1 exhibited robust expression in those samples harboring the amplicon, whereas LETM2 showed low and inconsistent expression in the presence or absence of amplification. FGFR1 showed an expression pattern that was consistent with placement outside the amplicon MCR.
To evaluate further the relevance of WHSC1L1 relative to FGFR1 in lung cancer, the biological impact of siRNA-mediated knockdown of each target was assessed in cell lines with and without $8 \mathrm{p}$ amplification (NCIH1703 and NCI-H1395, respectively). For all genes, RTQPCR documented $>70 \%$ knockdown following SMART siRNA pool transduction (data not shown). In soft agar assays with NCI-H1703, siRNA-mediated knockdown of WHSC1L1 resulted in 50\% reduction in the number of H1703 soft agar colonies, whereas near complete FGFR1 depletion had no impact on colony formation in soft agar. As expected, knockdown of these two genes had no effect on NCI-H1395 colony formation. The copy-number-driven expression data, coupled with knockdown studies, argue against a role for FGFR1 in lung cancers harboring an $8 \mathrm{p}$ amplicon and point to another gene, WHSC1L1, as the potential target of the amplification event.

Another amplicon present in both NSCLC and PDAC mapped to 20q11.2 and was detected in one primary lung $\mathrm{AC}$, one adenosquamous cell line, one SCC cell line, and 2 AC cell lines. These samples together delimited the MCR to $220 \mathrm{~kb}$, spanning position 29.66 to $29.88 \mathrm{Mb}$ and containing five genes: ID1, COX4I2, BCL2L1, TPX2, and MYLK2. Although BCL2L1, a known oncogene implicated in multiple cancer types, indeed exhibited modestly elevated expression, another gene in the amplicon, TPX2, showed high-level expression in most lung cell lines and primary tumors tested, even in the absence of amplification, when compared with RNA derived from normal lung (Fig. 8). These findings suggest that, in addition to a known oncogene BCL2L1, TPX2 is a potential candidate oncogene targeted for amplification in both lung and pancreas cancers.

\section{DISCUSSION}

This study has revealed a highly complex and rearranged NSCLC genome with many previously unrecognized regions of amplification and deletion with potential pathogenetic relevance to this lethal disease. In particular, we have identified and defined 93 high-confidence

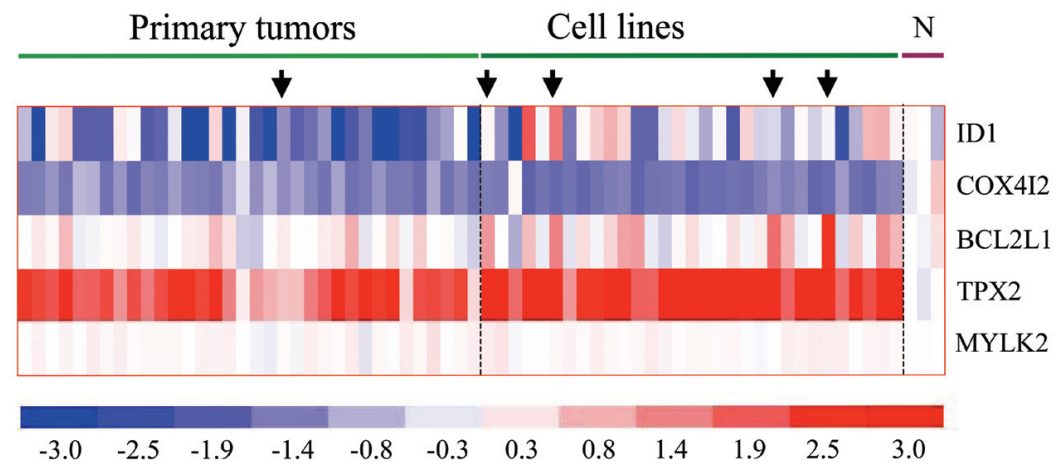

Figure 8. Expression analyses of genes residing in the chromosome 20q11 amplicon. Heat map representation of the expression level of each of the five genes, ID1, COX4I2, BCL2L1, TPX2, and MYLK2, in the amplicon from Affymetrix analysis. When multiple Affymetrix probes for a gene were present, the median value among the probes was used. Each column represents an individual sample, and each row represents a gene. The color intensity on the heat map correlates with the intensity of the expression, red representing overexpression and blue indicating reduced expression. The arrows indicate the samples that present amplification. (Reprinted, with permission, from Tonon et al. 2005 [CNational Academy of Sciences].) 
CNAs. It is notable that $22 \%$ of these span less than 0.5 $\mathrm{Mb}$ with a median of five resident genes. The significance of these findings rests on the fact that, to date, only a limited number of genes have been shown to be critical for the pathogenesis and maintenance of non-small-cell lung cancer (Minna et al. 2002). The identification, based on integrated DNA-RNA analyses, of candidate targets with plausible or known links to cancers resident within these focal CNAs reinforces the validity of the approach employed in this study.

Upon analysis of the highly focal CNAs, a number of genes emerged as strong oncogene and tumor suppressor gene candidates. Most notable were two loci harboring genes with structural similarity to known cancer genes: TPTE, related to PTEN (Walker et al. 2001), and BRD9, a bromodomain protein, related to BRD4 (You et al. 2004). Indeed, BRD4 mapped to a high-confidence MCR spanning 1.2 $\mathrm{Mb}$ on chromosome 19 and showed highlevel expression (Table 1). Other genes located within these small amplicons and showing a strong correlation with expression level included YRDC, a ribosome maturation factor, and Laminin Beta 3, which has been shown to be overexpressed in NSCLC cell lines (Manda et al. 2000). In addition, three recently described cyclins of unknown function-J, M3, and M4 - resided in two different MCRs and all showed overexpression. Other notable genes residing in the focal MCRs included members of the semaphorin family, in two different amplicons, and proteins involved in the desmosome structure, as Desmocollin 1 and 2, and Desmoglein 2. ERBB3 was among the genes showing copy-number-driven expression, consistent with recent reports of ERBB3 overexpression in NSCLC (Amann et al. 2005; Muller-Tidow et al. 2005). Indeed, all of the above mentioned genes showed copynumber-driven expression, and further analysis through Oncomine (Rhodes et al. 2004) showed that most of these genes were significantly deregulated in other cancer types relative to normal tissue controls. Finally, it is worth emphasizing that, in a number of the cases cited above, highly related genes were targeted in distinct amplification and deletion events in different tumor samples, suggesting that these functionally related molecules are critical in the development of NSCLC.

Our high-resolution genome-wide analysis has also uncovered a difference in overall genomic complexity between the two major subtypes of NSCLC. Specifically, the SCC subtype harbors genomic features suggestive of a much higher degree of genomic instability compared to the AC subtype, consistent with previous reports (Massion et al. 2002). Yet, it is striking that despite these widespread genomic differences, only one chromosomal region, at 3q26-q29, is consistently different between these two histological phenotypes, as previously suggested (Petersen et al. 1997; Bjorkqvist et al. 1998b; Luk et al. 2001; Pei et al. 2001; Balsara and Testa 2002; Massion et al. 2002). Of potential significance is the observation that this region has been reported to be the most common and early genetic alteration in SCC of the head and neck, a group of tumors that share similar developmental, histological, and pathogenetic features with SCCs of the lung (Huang et al. 2002). One potential explanation for this similarity is that these two histological subtypes of lung cancer are derived from the same lung stem/precursor cell and that only a few unique genetic alterations are sufficient to confer either an AC or a SCC phenotype. Indeed, there is some experimental evidence that the alveolar type II cell is a pluripotential stem cell involved in the genesis of both human AC and SCC (Ten Have-Opbroek et al. 1997). Our results suggest that, in a subset of lung SCCs, overexpression of genes residing within 3q, mediated either by amplification or by other mechanisms, could selectively induce a squamous cell phenotype against the backdrop of a genetic background that is otherwise common between ACs and SCCs. Interestingly, among the genes that did show overexpression in SCC samples irrespectively of copy number changes, there was p63. Overexpression of p63 has been reported in several squamous carcinomas (Massion et al. 2003; McKeon 2004), and mutations in p63 have been reported in human genetic disorders affecting ectodermal development (Westfall and Pietenpol 2004). In the mouse, p63 deficiency leads to profound defects or frank loss of the entire spectrum of epithelial tissues (McKeon 2004). Conditional transgenic mice expressing p63 isoforms in the epithelial lining of the bronchioles developed severe squamous metaplasia in the lung (Koster et al. 2004). These collective findings support the view that $\mathrm{p} 63$ exerts a critical role in maintaining the proliferative capacity of epidermal cell population as well as driving an epithelial stratification program (McKeon 2004). On the basis of our data and the prerogatives of the genes overexpressed in $3 \mathrm{q}$, it is tempting to speculate that AC and SCC arise from a common cellular origin and are driven to a malignant end point by common genetic and biological mechanisms.

Despite this discovery advance, this very large number of amplifications in human lung cancer presents significant challenges in prioritizing those amplified oncogenes for in-depth validation and ultimate enlistment into drug discovery and development. Given the common and overlapping role of many bona fide oncogenes or tumor suppressor genes across multiple cancer types, we tested the assumption that the comparison with array-CGH data sets from other cancer types could identify common CNAs harboring highly important oncogenes or tumor suppressor genes. To this end, we compared the NSCLC genome with that of pancreatic ductal adenocarcinoma (PA) (Aguirre et al. 2004). These comparisons identified several loci that are known to be commonly targeted in these cancers, including KRAS, c-MYC, and INK4a/ARF loci, as well as other loci not described previously.

Although novel for NSCLC, the amplicon on chromosome $8 \mathrm{p}$ has been observed in several other cancer types, including breast, prostate, bladder carcinomas, and T-cell lymphomas (Dib et al. 1995; Simon et al. 2001; Edwards et al. 2003; Mao et al. 2003; Ray et al. 2004). Although FGFR1 resides within this larger CNA and has been considered the prime candidate target of this amplification, detailed QPCR and FISH mapping performed in this study defined both boundaries and narrowed the minimal common region that excludes the FGFR1 gene.

Gene dosage alterations represent a common mecha- 
nism of oncogene activation and tumor suppressor inactivation by modulating expression of their target genes. Thus, integration of DNA copy number with expression provides a powerful early filter for culling bystanders of CNAs. In other words, it seems reasonable to assume that the true target of a CNA would exhibit altered expression in a copy-number-driven manner. However, definition of over- or underexpressed levels is itself a major challenge, particularly in cases where the true cell of origin remains unknown, and thus a premalignant physiological frame of reference is not available. In this study, we utilized three independent normal RNA references, isolated from adjacent histologically normal lung tissues (data not shown). Using such as reference, one can tentatively eliminate LETM2 as a candidate for this amplicon based on its lack of overexpression despite increased copy number (Fig. 7). Correspondingly, expression analysis demonstrated that FGFR1 was not overexpressed in most of the samples harboring this amplicon, and sequence analysis of exons encoding the juxtamembrane and kinase domains of FGFR1 failed to reveal any mutations. These findings in lung cancer are consistent with recent studies in breast cancer showing that FGFR1 does not play a pathogenetic role in breast cancer cells harboring amplification of this 8p locus (Dib et al. 1995; Ray et al. 2004), thereby pointing to other resident gene(s) as the true target of this 8p12-p11.2.

The gene that appears to be the most likely candidate target for this amplicon is WHSC1L1, on the basis of the physical mapping data, copy-driven expression patterns, and functional assay results. Additionally, data from the literature strongly point to this gene as causally involved in hematological and solid tumors. WHSC1L1 is involved in a chromosomal translocation in acute myeloid leukemia, $\mathrm{t}(8 ; 11)(\mathrm{p} 11.2 ; \mathrm{p} 15)$, that preserves all the domains in WHSC1L1 excluding one PWWP domain (Rosati et al. 2002). In addition, amplification of WHSC1L1 has been demonstrated in breast cancer (Angrand et al. 2001). Several members of the SET2 family of histone lysine methyltransferases, to which this gene belongs, have roles in cancer (Schneider et al. 2002). In particular, the two homologs of WHSC1L1, NSD1 and WHSC1, have been implicated in acute myeloid leukemia and multiple myeloma, respectively (Stec et al. 1998; Jaju et al. 2001). Together, these data provide a compelling case for WHSC1L1 as a novel lung cancer oncogene and as a prime target for amplification in NSCLC.

The chromosome 20 amplicon MCR contained five genes, and only BCL2L1 (known as BCL-xL) and TPX2 showed copy-number-driven expression. The identification of BCL2L1 suggests that gene amplification is one of the mechanisms driving BCL2L1 activation in NSCLC. The relevance of BCL2L1 amplification and overexpression in the development of NSCLC is strengthened by previous studies establishing a critical oncogenic role for BCL2L1 in PDAC (Bold et al. 2001; Xu et al. 2001; Trauzold et al. 2003). TPX2 is also a strong candidate target for amplification, and its frequent overexpression is observed in the presence or absence of amplification. TPX2 is required for targeting Aurora A kinase to the spindle apparatus. Elevated expression of Aurora A has been reported in breast, bladder, colon, ovarian, and pancreatic cancers and correlates with chromosomal instability and clinically aggressive disease. Up to $62 \%$ of breast cancers overexpress Aurora A, even where gene amplification is not detected. Elevated Aurora A expression causes abnormalities in mitosis and chromosome segregation and ectopically expressed Aurora A can transform rodent cells (Bischoff et al. 1998; Miyoshi et al. 2001; Anand et al. 2003). However, no reports of specific amplification or overexpression of this gene have been reported so far in NSCLC, a finding consistent with the absence of Aurora Kinase A gene amplification in our data set. TPX2 activates Aurora Kinase A (Gruss et al. 2002) and when overexpressed, it induces accumulation of cells in $\mathrm{G}_{2}-\mathrm{M}$ phase and polyploidization (Heidebrecht et al. 2003). Manda et al. (1999) have demonstrated that this gene is overexpressed in lung cancer tissue when compared with normal lung. TPX2 expression is tightly correlated with poor prognosis in patients with neuroblastoma (Krams et al. 2003). Additionally, using Oncomine (Rhodes et al. 2004), we compared the expression level of TPX2 in different cancer types to the corresponding levels in normal tissues. Lung SCCs and ACs, lung small-cell carcinomas (Bhattacharjee et al. 2001; Garber et al. 2001), as well as prostate (Dhanasekaran et al. 2001; LaTulippe et al. 2002) and hepatocellular carcinoma (Chen et al. 2002) showed significant overexpression of TPX2 when compared with the respective normal tissues. Intriguingly, in our expression data, a high correlation existed between TPX2 and Aurora Kinase A expression ( $\mathrm{r}=0.7801$, $p<0.001)$ and even more with many other genes involved in spindle formation and mitotic progression, as for example, Bub1 ( $\mathrm{r}=0.93, p<0.001), \mathrm{CDC} 20$ ( $\mathrm{r}=0.93$, $p<0.001)$, Aurora Kinase B $(\mathrm{r}=0.90, p<0.001)$. The amplification of TPX2 and the correlation of its expression with genes involved in spindle formation and progression through the cell cycle suggest a possible critical role for TPX2 in lung and pancreas carcinogenesis.

In conclusion, using gene-specific CGH platforms and novel custom bioinformatics tools, along with integration of expression profiles, we have identified many new recurrent amplifications and deletions in the NSCLC genome. The high degree of NSCLC genomic complexity, the recurrent nature of these lesions, and preliminary functional characterization of resident genes support the view that a large number of important oncogenes and tumor suppressor genes remain to be identified, opening potential therapeutic and diagnostic opportunities for this dismal disease.

\section{ACKNOWLEDGMENTS}

We are grateful to Drs. Ruben Carrasco, Elizabeth Maher, Ergun Sahin, Omar Kabbarah, Mariela Jaskelioff, and Aram Hezel for helpful discussions and manuscript revisions, and to Chris Leo, Melissa Donovan, and Ilana Perna for superb technical advice and support. ArrayCGH profiles were performed at the Arthur and Rochelle Belfer Cancer Genomic Center at Dana-Farber Cancer Institute. G.T. is supported by a grant from The Fund to 
Cure Myeloma and a SPORE Multiple Myeloma Career Development Award. K.K.W. is supported by a National Institutes of Health (NIH) grant K08AG 2400401, the Sidney Kimmel Foundation for Cancer Research, and the Joan Scarangello Foundation to Conquer Lung Cancer. L.C. is supported by NIH grants RO1 CA099041 and UO1 U01-CA084313-07. R.A.D. is an American Cancer Society Research Professor and an Ellison Medical Foundation Senior Scholar and is supported by grants from the American Cancer Society and the NIH (U01-CA08431307 and R01 CA084628-12).

\section{REFERENCES}

Aguirre A.J., Brennan C., Bailey G., Sinha R., Feng B., Leo C., Zhang Y., Zhang J., Gans J.D., Bardeesy N., Cauwels C., Cordon-Cardo C., Redston M.S., DePinho R.A., and Chin L. 2004. High-resolution characterization of the pancreatic adenocarcinoma genome. Proc. Natl. Acad. Sci. 101: 9067.

Albertson D.G. and Pinkel D. 2003. Genomic microarrays in human genetic disease and cancer. Hum. Mol. Genet. 12: 145R.

Amann J., Kalyankrishna S., Massion P.P., Ohm J.E., Girard L., Shigematsu H., Peyton M., Juroske D., Huang Y., Stuart Salmon J., Kim Y.H., Pollack J.R., Yanagisawa K., Gazdar A., Minna J.D., Kurie J.M., and Carbone D.P. 2005. Aberrant epidermal growth factor receptor signaling and enhanced sensitivity to EGFR inhibitors in lung cancer. Cancer Res. 65: 226.

Anand S., Penrhyn-Lowe S., and Venkitaraman A.R. 2003. AURORA-A amplification overrides the mitotic spindle assembly checkpoint, inducing resistance to Taxol. Cancer Cell 3: 51 .

Angrand P.O., Apiou F., Stewart A.F., Dutrillaux B., Losson R., and Chambon P. 2001. NSD3, a new SET domain-containing gene, maps to $8 \mathrm{p} 12$ and is amplified in human breast cancer cell lines. Genomics 74: 79.

Balsara B.R. and Testa J.R. 2002. Chromosomal imbalances in human lung cancer. Oncogene 21: 6877.

Bhattacharjee A., Richards W.G., Staunton J., Li C., Monti S., Vasa P., Ladd C., Beheshti J., Bueno R., Gillette M., Loda M., Weber G., Mark E.J., Lander E.S., Wong W., Johnson B.E., Golub T.R., Sugarbaker D.J., and Meyerson M. 2001. Classification of human lung carcinomas by mRNA expression profiling reveals distinct adenocarcinoma subclasses. Proc. Natl. Acad. Sci. 98: 13790

Bischoff J.R., Anderson L., Zhu Y., Mossie K., Ng L., Souza B., Schryver B., Flanagan P., Clairvoyant F., Ginther C., Chan C.S., Novotny M., Slamon D.J., and Plowman G.D. 1998. A homologue of Drosophila aurora kinase is oncogenic and amplified in human colorectal cancers. EMBO J. 17: 3052.

Bjorkqvist A.M., Tammilehto L., Nordling S., Nurminen M., Anttila S., Mattson K., and Knuutila S. 1998a. Comparison of DNA copy number changes in malignant mesothelioma, adenocarcinoma and large-cell anaplastic carcinoma of the lung. Br. J. Cancer 77: 260.

Bjorkqvist A.M., Husgafvel-Pursiainen K., Anttila S., Karjalainen A., Tammilehto L., Mattson K., Vainio H., and Knuutila S. 1998b. DNA gains in 3q occur frequently in squamous cell carcinoma of the lung, but not in adenocarcinoma. Genes Chromosomes Cancer 22: 79.

Bold R.J., Virudachalam S., and McConkey D.J. 2001. BCL2 expression correlates with metastatic potential in pancreatic cancer cell lines. Cancer 92: 1122.

Calin G.A., Sevignani C., Dumitru C.D., Hyslop T., Noch E., Yendamuri S., Shimizu M., Rattan S., Bullrich F., Negrini M., and Croce C.M. 2004a. Human microRNA genes are frequently located at fragile sites and genomic regions involved in cancers. Proc. Natl. Acad. Sci. 101: 2999.

Calin G.A., Liu C.G., Sevignani C., Ferracin M., Felli N., Dumitru C.D., Shimizu M., Cimmino A., Zupo S., Dono M., Dell'Aquila M.L., Alder H., Rassenti L., Kipps T.J., Bullrich F., Negrini M., and Croce C.M. 2004b. MicroRNA profiling reveals distinct signatures in B cell chronic lymphocytic leukemias. Proc. Natl. Acad. Sci. 101: 11755.

Chen X., Cheung S.T., So S., Fan S.T., Barry C., Higgins J., Lai K.M., Ji J., Dudoit S., Ng I.O., Van De Rijn M., Botstein D., and Brown P.O. 2002. Gene expression patterns in human liver cancers. Mol. Biol. Cell 13: 1929.

Danilkovitch-Miagkova A., Duh F.M., Kuzmin I., Angeloni D., Liu S.L., Miller A.D., and Lerman M.I. 2003. Hyaluronidase 2 negatively regulates RON receptor tyrosine kinase and mediates transformation of epithelial cells by jaagsiekte sheep retrovirus. Proc. Natl. Acad. Sci. 100: 4580.

Dhanasekaran S.M., Barrette T.R., Ghosh D., Shah R., Varambally S., Kurachi K., Pienta K.J., Rubin M.A., and Chinnaiyan A.M. 2001. Delineation of prognostic biomarkers in prostate cancer. Nature 412: 822.

Dib A., Adelaide J., Chaffanet M., Imbert A., Le Paslier D., Jacquemier J., Gaudray P., Theillet C., Birnbaum D., and Pebusque M.J. 1995. Characterization of the region of the short arm of chromosome 8 amplified in breast carcinoma. Oncogene 10: 995.

Edwards J., Krishna N.S., Witton C.J., and Bartlett J.M. 2003. Gene amplifications associated with the development of hormone-resistant prostate cancer. Clin. Cancer Res. 9: 5271.

Futreal P.A., Coin L., Marshall M., Down T., Hubbard T., Wooster R., Rahman N., and Stratton M.R. 2004. A census of human cancer genes. Nat. Rev. Cancer 4: 177.

Garber M.E., Troyanskaya O.G., Schluens K., Petersen S., Thaesler Z., Pacyna-Gengelbach M., van de Rijn M., Rosen G.D., Perou C.M., Whyte R.I., Altman R.B., Brown P.O., Botstein D., and Petersen I. 2001. Diversity of gene expression in adenocarcinoma of the lung. Proc. Natl. Acad. Sci. 98: 13784.

Gruss O.J., Wittmann M., Yokoyama H., Pepperkok R., Kufer T., Sillje H., Karsenti E., Mattaj I.W., and Vernos I. 2002. Chromosome-induced microtubule assembly mediated by TPX2 is required for spindle formation in HeLa cells. Nat. Cell Biol. 4: 871 .

He L., Thomson J.M., Hemann M.T., Hernando-Monge E., Mu D., Goodson S., Powers S., Cordon-Cardo C., Lowe S.W., Hannon G.J., and Hammond S.M. 2005. A microRNA polycistron as a potential human oncogene. Nature 435: 828.

Heidebrecht H.J., Adam-Klages S., Szczepanowski M., Pollmann M., Buck F., Endl E., Kruse M.L., Rudolph P., and Parwaresch R. 2003. repp86: A human protein associated in the progression of mitosis. Mol. Cancer Res. 1: 271.

Huang Q., Yu G.P., McCormick S.A., Mo J., Datta B., Mahimkar M., Lazarus P., Schaffer A.A., Desper R., and Schantz S.P. 2002. Genetic differences detected by comparative genomic hybridization in head and neck squamous cell carcinomas from different tumor sites: Construction of oncogenetic trees for tumor progression. Genes Chromosomes Cancer 34: 224.

Imreh S., Klein G., and Zabarovsky E.R. 2003. Search for unknown tumor-antagonizing genes. Genes Chromosomes Cancer 38: 307.

Jaju R.J., Fidler C., Haas O.A., Strickson A.J., Watkins F., Clark K., Cross N.C., Cheng J.F., Aplan P.D., Kearney L., Boultwood J., and Wainscoat J.S. 2001. A novel gene, NSD1, is fused to NUP98 in the $\mathrm{t}(5 ; 11)(\mathrm{q} 35 ; \mathrm{p} 15.5)$ in de novo childhood acute myeloid leukemia. Blood 98: 1264.

Kallioniemi O.P., Kallioniemi A., Piper J., Isola J., Waldman F.M., Gray J.W., and Pinkel D. 1994. Optimizing comparative genomic hybridization for analysis of DNA sequence copy number changes in solid tumors. Genes Chromosomes Cancer 10: 231.

Kashuba V.I., Li J., Wang F., Senchenko V.N., Protopopov A., Malyukova A., Kutsenko A.S., Kadyrova E., Zabarovska V.I., Muravenko O.V., Zelenin A.V., Kisselev L.L., Kuzmin I., Minna J.D., Winberg G., Ernberg I., Braga E., Lerman M.I., Klein G., and Zabarovsky E.R. 2004. RBSP3 (HYA22) is a tumor suppressor gene implicated in major epithelial malignancies. Proc. Natl. Acad. Sci. 101: 4906.

Koster M.I., Kim S., Mills A.A., DeMayo F.J., and Roop D.R. 2004. p63 is the molecular switch for initiation of an epithe- 
lial stratification program. Genes Dev. 18: 126.

Krams M., Heidebrecht H.J., Hero B., Berthold F., Harms D., Parwaresch R., and Rudolph P. 2003. Repp86 expression and outcome in patients with neuroblastoma. J. Clin. Oncol. 21: 1810.

LaTulippe E., Satagopan J., Smith A., Scher H., Scardino P., Reuter V., and Gerald W.L. 2002. Comprehensive gene expression analysis of prostate cancer reveals distinct transcriptional programs associated with metastatic disease. Cancer Res. 62: 4499.

Lerman M.I. and Minna J.D. 2000. The 630-kb lung cancer homozygous deletion region on human chromosome $3 \mathrm{p} 21.3$ : Identification and evaluation of the resident candidate tumor suppressor genes. The International Lung Cancer Chromosome 3p21.3 Tumor Suppressor Gene Consortium. Cancer Res. 60: 6116.

Lu J., Getz G., Miska E.A., Alvarez-Saavedra E., Lamb J., Peck D., Sweet-Cordero A., Ebert B.L., Mak R.H., Ferrando A.A., Downing J.R., Jacks T., Horvitz H.R., and Golub T.R. 2005. MicroRNA expression profiles classify human cancers. $\mathrm{Na}$ ture 435: 834.

Luk C., Tsao M.S., Bayani J., Shepherd F., and Squire J.A. 2001. Molecular cytogenetic analysis of non-small cell lung carcinoma by spectral karyotyping and comparative genomic hybridization. Cancer Genet. Cytogenet. 125: 87.

Lynch T.J., Bell D.W., Sordella R., Gurubhagavatula S., Okimoto R.A., Brannigan B.W., Harris P.L., Haserlat S.M., Supko J.G., Haluska F.G., Louis D.N., Christiani D.C., Settleman J., and Haber D.A. 2004. Activating mutations in the epidermal growth factor receptor underlying responsiveness of non-small-cell lung cancer to gefitinib. N. Engl. J. Med. 350: 2129.

Manda R., Kohno T., Matsuno Y., Takenoshita S., Kuwano H., and Yokota J. 1999. Identification of genes (SPON2 and C20orf2) differentially expressed between cancerous and noncancerous lung cells by mRNA differential display. Genomics 61: 5 .

Manda R., Kohno T., Niki T., Yamada T., Takenoshita S., Kuwano H., and Yokota J. 2000. Differential expression of the LAMB3 and LAMC2 genes between small cell and nonsmall cell lung carcinomas. Biochem. Biophys. Res. Commun. 275: 440 .

Mao X., Onadim Z., Price E.A., Child F., Lillington D.M., Russell-Jones R., Young B.D., and Whittaker S. 2003. Genomic alterations in blastic natural killer/extranodal natural killerlike T cell lymphoma with cutaneous involvement. J. Invest. Dermatol. 121: 618.

Massion P.P., Taflan P.M., Jamshedur Rahman S.M., Yildiz P., Shyr Y., Edgerton M.E., Westfall M.D., Roberts J.R., Pietenpol J.A., Carbone D.P., and Gonzalez A.L. 2003. Significance of p63 amplification and overexpression in lung cancer development and prognosis. Cancer Res. 63: 7113.

Massion P.P., Kuo W.L., Stokoe D., Olshen A.B., Treseler P.A., Chin K., Chen C., Polikoff D., Jain A.N., Pinkel D., Albertson D.G., Jablons D.M., and Gray J.W. 2002. Genomic copy number analysis of non-small cell lung cancer using array comparative genomic hybridization: Implications of the phosphatidylinositol 3-kinase pathway. Cancer Res. 62: 3636.

McKeon F. 2004. p63 and the epithelial stem cell: More than status quo? Genes Dev. 18: 465.

Metzler M., Wilda M., Busch K., Viehmann S., and Borkhardt A. 2004. High expression of precursor microRNA-155/BIC RNA in children with Burkitt lymphoma. Genes Chromosomes Cancer 39: 167.

Minna J.D., Roth J.A., and Gazdar A.F. 2002. Focus on lung cancer. Cancer Cell 1: 49.

Miyoshi Y., Iwao K., Egawa C., and Noguchi S. 2001. Association of centrosomal kinase STK15/BTAK mRNA expression with chromosomal instability in human breast cancers. Int. J. Cancer 92: 370.

Muller-Tidow C., Diederichs S., Bulk E., Pohle T., Steffen B., Schwable J., Plewka S., Thomas M., Metzger R., Schneider P.M., Brandts C.H., Berdel W.E., and Serve H. 2005. Identification of metastasis-associated receptor tyrosine kinases in non-small cell lung cancer. Cancer Res. 65: 1778.

O’Donnell K.A., Wentzel E.A., Zeller K.I., Dang C.V., and Mendell J.T. 2005. c-Myc-regulated microRNAs modulate E2F1 expression. Nature 435: 839.

Olshen A.B., Venkatraman E.S., Lucito R., and Wigler M. 2004. Circular binary segmentation for the analysis of array-based DNA copy number data. Biostatistics 5: 557.

Paez J.G., Janne P.A., Lee J.C., Tracy S., Greulich H., Gabriel S., Herman P., Kaye F.J., Lindeman N., Boggon T.J., Naoki K., Sasaki H., Fujii Y., Eck M.J., Sellers W.R., Johnson B.E., and Meyerson M. 2004. EGFR mutations in lung cancer: Correlation with clinical response to gefitinib therapy. Science 304: 1497.

Pei J., Balsara B.R., Li W., Litwin S., Gabrielson E., Feder M., Jen J., and Testa J.R. 2001. Genomic imbalances in human lung adenocarcinomas and squamous cell carcinomas. Genes Chromosomes Cancer 31: 282.

Petersen I., Bujard M., Petersen S., Wolf G., Goeze A., Schwendel A., Langreck H., Gellert K., Reichel M., Just K., du Manoir S., Cremer T., Dietel M., and Ried T. 1997. Patterns of chromosomal imbalances in adenocarcinoma and squamous cell carcinoma of the lung. Cancer Res. 57: 2331.

Pollack J.R., Perou C.M., Alizadeh A.A., Eisen M.B., Pergamenschikov A., Williams C.F., Jeffrey S.S., Botstein D., and Brown P.O. 1999. Genome-wide analysis of DNA copy-number changes using cDNA microarrays. Nat. Genet. 23: 41.

Pollack J.R., Sorlie T., Perou C.M., Rees C.A., Jeffrey S.S., Lonning P.E., Tibshirani R., Botstein D., Borresen-Dale A.L., and Brown P.O. 2002. Microarray analysis reveals a major direct role of DNA copy number alteration in the transcriptional program of human breast tumors. Proc. Natl. Acad. Sci. 99: 12963.

Protopopov A., Kashuba V., Zabarovska V.I., Muravenko O.V., Lerman M.I., Klein G., and Zabarovsky E.R. 2003. An integrated physical and gene map of the $3.5-\mathrm{Mb}$ chromosome 3 p21.3 (AP20) region implicated in major human epithelial malignancies. Cancer Res. 63: 404.

Ray M.E., Yang Z.Q., Albertson D., Kleer C.G., Washburn J.G., Macoska J.A., and Ethier S.P. 2004. Genomic and expression analysis of the 8p11-12 amplicon in human breast cancer cell lines. Cancer Res. 64: 40.

Rhodes D.R., Yu J., Shanker K., Deshpande N., Varambally R., Ghosh D., Barrette T., Pandey A., and Chinnaiyan A.M. 2004. ONCOMINE: A cancer microarray database and integrated data-mining platform. Neoplasia 6: 1 .

Rosati R., La Starza R., Veronese A., Aventin A., Schwienbacher C., Vallespi T., Negrini M., Martelli M.F., and Mecucci C. 2002. NUP98 is fused to the NSD3 gene in acute myeloid leukemia associated with $\mathrm{t}(8 ; 11)(\mathrm{p} 11.2 ; \mathrm{p} 15)$. Blood 99: 3857.

Samuels Y., Wang Z., Bardelli A., Silliman N., Ptak J., Szabo S., Yan H., Gazdar A., Powell S.M., Riggins G.J., Willson J.K., Markowitz S., Kinzler K.W., Vogelstein B., and Velculescu V.E. 2004. High frequency of mutations of the PIK3CA gene in human cancers. Science 304: 554.

Schneider R., Bannister A.J., and Kouzarides T. 2002. Unsafe SETs: Histone lysine methyltransferases and cancer. Trends Biochem. Sci. 27: 396.

Sebat J., Lakshmi B., Troge J., Alexander J., Young J., Lundin P., Maner S., Massa H., Walker M., Chi M., Navin N., Lucito R., Healy J., Hicks J., Ye K., Reiner A., Gilliam T.C., Trask B., Patterson N., Zetterberg A., and Wigler M. 2004. Largescale copy number polymorphism in the human genome. Science 305: 525.

Simon R., Richter J., Wagner U., Fijan A., Bruderer J., Schmid U., Ackermann D., Maurer R., Alund G., Knonagel H., Rist M., Wilber K., Anabitarte M., Hering F., Hardmeier T., Schonenberger A., Flury R., Jager P., Fehr J.L., Schraml P., Moch H., Mihatsch M.J., Gasser T., and Sauter G. 2001. Highthroughput tissue microarray analysis of 3p25 (RAF1) and 8p12 (FGFR1) copy number alterations in urinary bladder cancer. Cancer Res. 61: 4514.

Stec I., Wright T.J., van Ommen G.J., de Boer P.A., van Haeringen A., Moorman A.F., Altherr M.R., and den Dunnen J.T. 
1998. WHSC1, a 90 kb SET domain-containing gene, expressed in early development and homologous to a Drosophila dysmorphy gene maps in the Wolf-Hirschhorn syndrome critical region and is fused to $\operatorname{IgH}$ in $\mathrm{t}(4 ; 14)$ multiple myeloma. Hum. Mol. Genet. 7: 1071 .

Storey J.D. and Tibshirani R. 2003. Statistical significance for genomewide studies. Proc. Natl. Acad. Sci. 100: 9440.

Ten Have-Opbroek A.A., Benfield J.R., van Krieken J.H., and Dijkman J.H. 1997. The alveolar type II cell is a pluripotential stem cell in the genesis of human adenocarcinomas and squamous cell carcinomas. Histol. Histopathol. 12: 319.

Tonon G., Wong K.K., Maulik G., Brennan C., Feng B., Zhang Y., Khatry D.B., Protopopov A., You M.J., Aguirre A.J., Martin E.S., Yang Z., Ji H., Chin L., and Depinho R.A. 2005. High-resolution genomic profiles of human lung cancer. Proc. Natl. Acad. Sci. 102: 9625.

Trauzold A., Schmiedel S., Roder C., Tams C., Christgen M., Oestern S., Arlt A., Westphal S., Kapischke M., Ungefroren H., and Kalthoff H. 2003. Multiple and synergistic deregulations of apoptosis-controlling genes in pancreatic carcinoma cells. Br. J. Cancer 89: 1714.

Tusher V.G., Tibshirani R., and Chu G. 2001. Significance analysis of microarrays applied to the ionizing radiation response.
Proc. Natl. Acad. Sci. 98: 5116.

Walker S.M., Downes C.P., and Leslie N.R. 2001. TPIP: A novel phosphoinositide 3-phosphatase. Biochem. J. 360: 277.

Westfall M.D. and Pietenpol J.A. 2004. p63: Molecular complexity in development and cancer. Carcinogenesis 25: 857.

Xu Z., Friess H., Solioz M., Aebi S., Korc M., Kleeff J., and Buchler M.W. 2001. Bcl-x(L) antisense oligonucleotides induce apoptosis and increase sensitivity of pancreatic cancer cells to gemcitabine. Int. J. Cancer 94: 268.

You J., Croyle J.L., Nishimura A., Ozato K., and Howley P.M. 2004. Interaction of the bovine papillomavirus E2 protein with Brd4 tethers the viral DNA to host mitotic chromosomes. Cell 117: 349.

Zabarovsky E.R., Lerman M.I., and Minna J.D. 2002. Tumor suppressor genes on chromosome $3 \mathrm{p}$ involved in the pathogenesis of lung and other cancers. Oncogene 21: 6915.

Zhao X., Weir B.A., LaFramboise T., Lin M., Beroukhim R., Garraway L., Beheshti J., Lee J.C., Naoki K., Richards W.G., Sugarbaker D., Chen F., Rubin M.A., Janne P.A., Girard L., Minna J., Christiani D., Li C., Sellers W.R., and Meyerson M. 2005. Homozygous deletions and chromosome amplifications in human lung carcinomas revealed by single nucleotide polymorphism array analysis. Cancer Res. 65: 5561. 


\section{$8_{8}^{\infty} \mathrm{CSH} \&$ Cold Spring Harbor Symposia SYMPOSIA on Quantitative Biology}

\section{Common and Contrasting Genomic Profiles among the Major Human Lung Cancer Subtypes}

G. TONON, C. BRENNAN, A. PROTOPOPOV, et al.

Cold Spring Harb Symp Quant Biol 2005 70: 11-24

Access the most recent version at doi:10.1101/sqb.2005.70.021

References This article cites 72 articles, 34 of which can be accessed free at: http://symposium.cshlp.org/content/70/11.full.html\#ref-list-1

License

Email Alerting Receive free email alerts when new articles cite this article - sign up in Service the box at the top right corner of the article or click here. 